\title{
Nanocellulose-Based Scaffolds for Chondrogenic Differentiation and Expansion
}

\section{OPEN ACCESS}

Edited by:

Selestina Gorgieva,

University of Maribor, Slovenia

Reviewed by:

Rajendra Kumar Singh,

Institute of Tissue Regeneration

Engineering (ITREN), South Korea

Katsuhiro Hosoyama,

Iwate Prefectural Central Hospital,

Japan

*Correspondence:

Edyta Gendaszewska-Darmach edyta.gendaszewska-darmach@ p.lodz.pl

Specialty section:

This article was submitted to Biomaterials,

a section of the journal Frontiers in Bioengineering and

Biotechnology

Received: 04 July 2021 Accepted: 03 August 2021 Published: 17 August 2021

Citation:

Szustak $M$ and

Gendaszewska-Darmach E (2021) Nanocellulose-Based Scaffolds for

Chondrogenic Differentiation

and Expansion.

Front. Bioeng. Biotechnol. 9:736213.

doi: 10.3389/fbioe.2021.736213

\section{Marcin Szustak and Edyta Gendaszewska-Darmach *}

Faculty of Biotechnology and Food Sciences, Institute of Molecular and Industrial Biotechnology, Lodz University of Technology, Lodz, Poland

Nanocellulose deserves special attention among the large group of biocompatible biomaterials. It exhibits good mechanical properties, which qualifies it for potential use as a scaffold imitating cartilage. However, the reconstruction of cartilage is a big challenge due to this tissue's limited regenerative capacity resulting from its lack of vascularization, innervations, and sparsely distributed chondrocytes. This feature restricts the infiltration of progenitor cells into damaged sites. Unfortunately, differentiated chondrocytes are challenging to obtain, and mesenchymal stem cells have become an alternative approach to promote chondrogenesis. Importantly, nanocellulose scaffolds induce the differentiation of stem cells into chondrocyte phenotypes. In this review, we present the recent progress of nanocellulose-based scaffolds promoting the development of cartilage tissue, especially within the emphasis on chondrogenic differentiation and expansion.

Keywords: cartilage, tissue engineering, nanocellulose, chondrocytes, stem cells, differentiation

\section{INTRODUCTION}

Despite possessing remarkable mechanical properties, articular cartilage has very limited regeneration capacity resulting from the lack of vascularization, lymphangion, innervations, and restricted infiltration of local progenitor cells. Moreover, the cartilage tissue is sparsely populated with chondrocytes embedded within an extracellular matrix (ECM) (Castañeda and Vicente, 2017). Therefore, articular cartilage injuries initiated both traumatically and with systemic diseases and aging, frequently progress to osteoarthritis (OA). In developing countries, osteoarthritis, characterized by gradual loss of articular cartilage, osteophyte formation, and other abnormalities, is a leading cause of chronic pain and disability. Currently, 250 million people are affected by OA due to the combined effects of increases in life expectancy, body mass index, and joint injuries (Hunter and Bierma-Zeinstra, 2019).

The available treatment options for articular cartilage damage include pharmacological intervention, primarily used for pain management and reducing stiffness, and surgical approaches to treat more advanced stages of cartilage injuries. However, common surgical interventions such as chondroplasty, microfracture, or drilling are effective only for minor defects and provide the relatively short-term functional improvement of joint mobility and reducing pain (Davies and Kuiper, 2019). Restoration of severe cartilage injuries is based on osteochondral autograft or allograft and autologous chondrocyte implantation (ACI). ACI was a breakthrough in the treatment of large articular cartilage defects. In this two-step procedure, chondrocytes are isolated from healthy cartilage (bioptate) and collected arthroscopically, expanded in vitro for 2-3 weeks as a monolayer, and embedded into the patient's damaged tissue with periosteum (Zylińska et al., 2018). Long-term results for first-generation ACI were generally poor, with no significant difference in comparison with microfracture. 20-years follow-up 


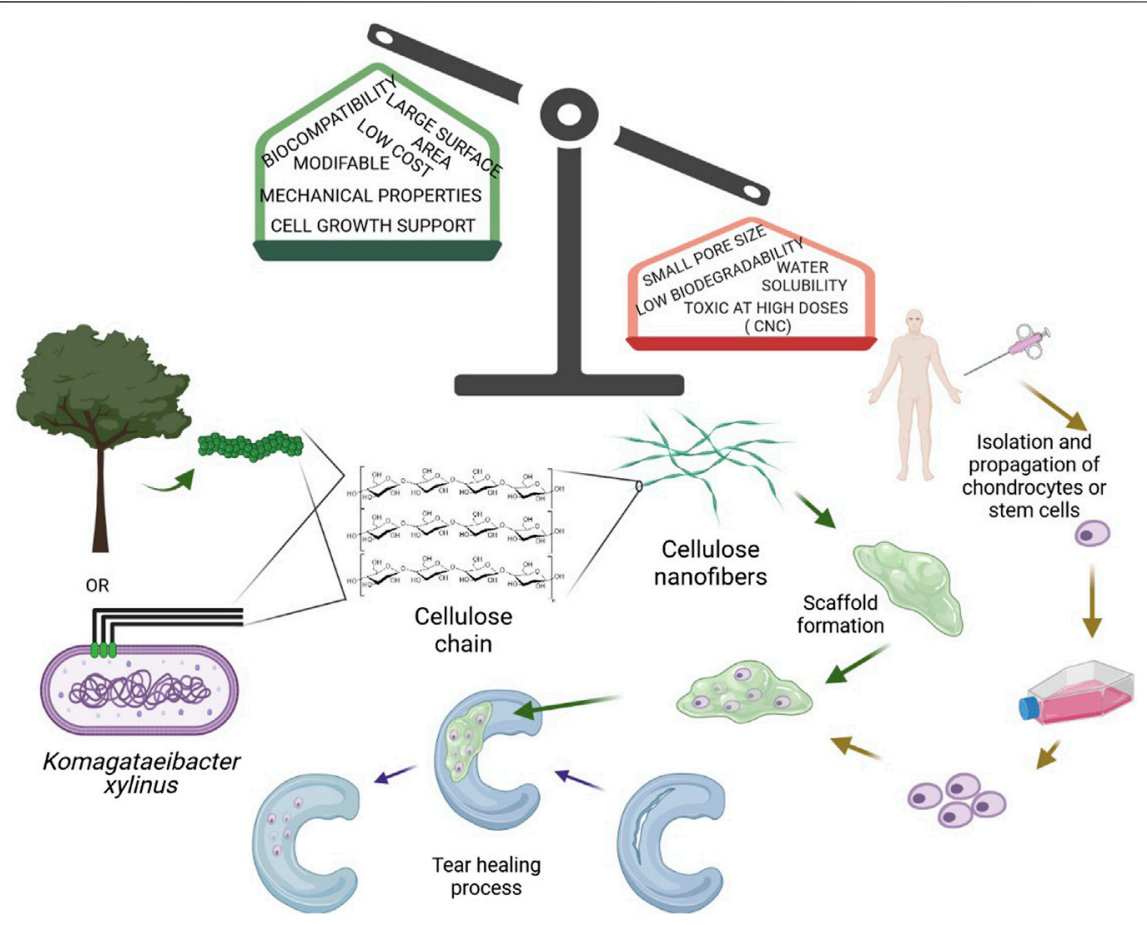

studies showed ACI failure in $37 \%$ of treated patients (Ogura et al., 2017). Notably, the critical limitations of ACI is dedifferentiation, defined as the loss of the chondrocyte phenotypes and the adaption of the fibroblast phenotypes during in vitro expansion (Mao et al., 2018). Results improved with second-generation techniques, in which a type I-III collagen membrane was used to cover the autologous chondrocytes, and third-generation scaffold-based ACI techniques termed MACI (matrix-induced autologous chondrocyte implantation) (Zylińska et al., 2018).

Following the promising clinical results of MACI, supported by advances in material and biomedical sciences, many unique compositions of scaffolds in cartilage tissue engineering have been proposed (Ngadimin et al., 2021; Zhao et al., 2021). Among natural biomaterials, particular attention has been given to nanocellulose (NC), regarded as "generally recognized as safe" by the U.S. Food and Drug Administration (Halib et al., 2017). Nanocellulose, as the main constituent of plant cell walls, is the most abundant biopolymer in nature. However, it is also synthesized by marine animals, algae, fungi, and several bacteria species (Halib et al., 2017). The most efficient bacterial cellulose producers are acetic acid bacteria of the Komagataeibacter genus (Ryngajłło et al., 2020). NC is promising due to its unique biomechanical and rheological properties, such as extraordinarily high stiffness and strength (Piras et al., 2017). Being also biocompatible, insoluble, elastic, and hydrophilic, nanocellulosic materials are of great interest in medical applications such as wound healing or reconstructive surgery of soft and hard tissues (Ludwicka et al., 2019). Numerous reviews have already been published on potential applications of nanocellulose in tissue engineering (Halib et al., 2017; Dutta et al., 2019; Gorgieva and Trček, 2019; Chinta et al., 2021), however, this review will firstly discuss the current state of knowledge in terms of nanocellulose and its composites as scaffolds for chondrogenic expansion and differentiation.

\section{TISSUE ENGINEERING IN CARTILAGE REGENERATION-MAIN ASSUMPTIONS}

In 1993 Langer and Vacanti defined tissue engineering (TE) as "a modern and interdisciplinary science that applies both the principles of engineering and the processes and phenomena of the life sciences toward the development of biological substitutes that restore, maintain, or improve tissue function" (Langer and Vacanti, 1993). Therefore, TE combines biology, clinical medicine, and materials science to produce artificial tissues or organs. In general, regenerative engineering aims to provide a temporary three-dimensional (3D) environment or "scaffold" for recruited or seeded cells to regenerate injured tissues. The tissue engineering triad consists of three critical components that work together to produce a successful construct. The first one, a biomaterial scaffold that temporarily imitates ECM, provides a 3D environment for cell attachment, proliferation, and differentiation. Numerous scaffold properties, such as architecture (e.g., pore size and shape), modulus, chemical functionality, hydrophobicity, and others, have been shown to affect cell phenotype and activity. Scaffolds with high porosity and pore interconnectivity are easily penetrated by cells and help diffusion 


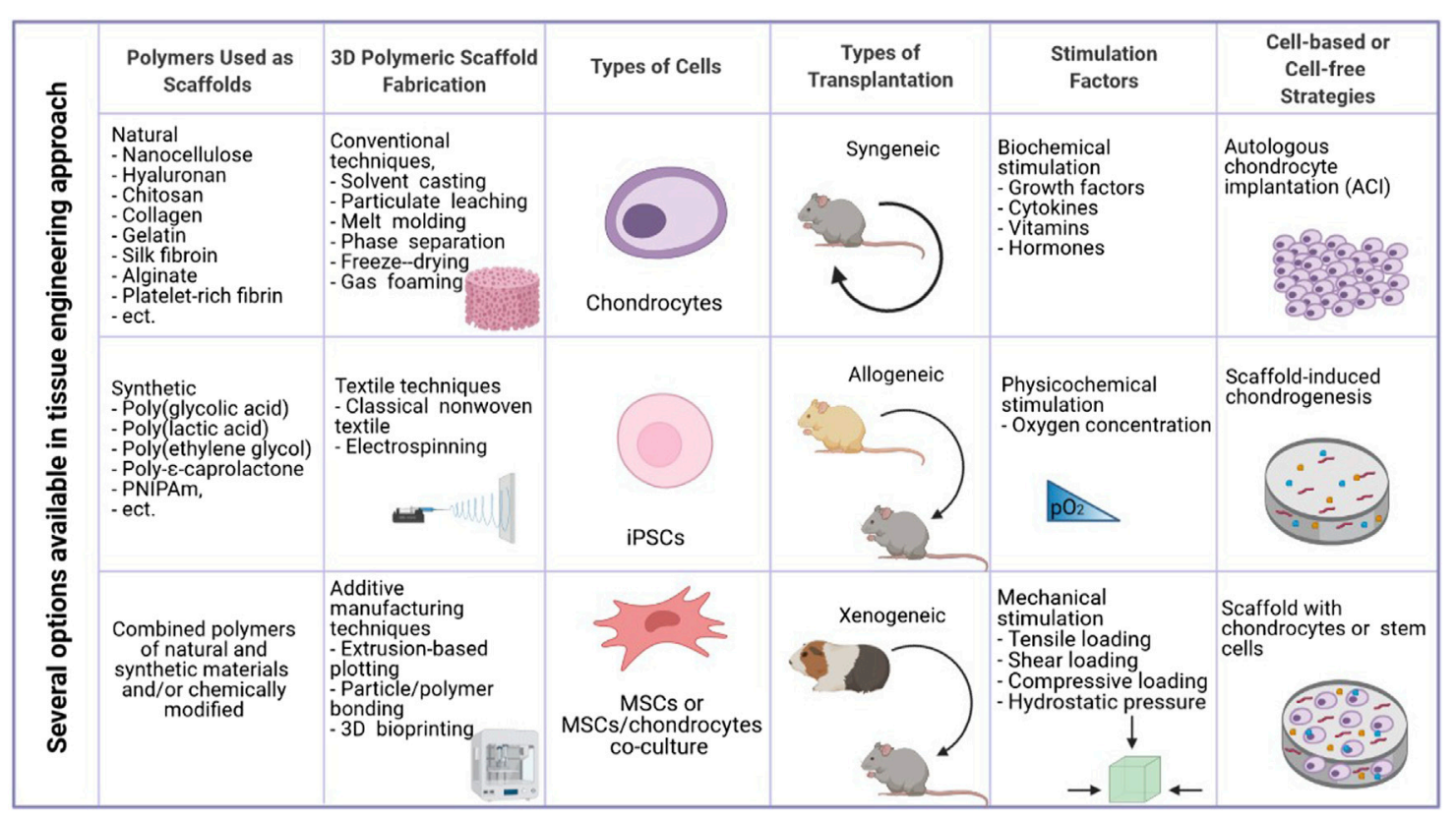

FIGURE 1 | Essential elements in cartilage tissue engineering (created in BioRender.com).

of nutrients and gases. A relevant collection of cells (stem cells, differentiated cells) serves as the second element while appropriate signals such as chemical mediators (vitamins, amino acids, hormones, growth factors, cytokines, and active drugs), mechanical (compression or pressure), and physicochemical factors (oxidative stress, carbon dioxide concentration, etc.) are the third component which affects cell viability and growth (James and Laurencin, 2014; Oprea and Voicu, 2020). A novel material-based regenerative approach relies solely on the chemical and physical properties of the scaffold to guide tissue regeneration (i.e., without exogenous growth factors) (Almouemen et al., 2019).

Given the limited spontaneous repair after cartilage injury, tissue engineering approaches for cartilage regeneration are becoming more common (Figure 1). Current cartilage TE techniques include two approaches. The first one involves the transplantation of natural tissue similar to cartilage. Autologous cell implantation is the most popular where patients' cells are collected from other body parts and located in lesions (Peterson et al., 2010). An obvious limitation of this method is connected with lowering cell viability with aging (Loeser et al., 2016). The second approach involves the fabrication of artificial cartilage with biochemical, biomechanical, and structural properties resembling natural tissue (Walter et al., 2019). Moreover, there exist two different methodologies for fabrication the scaffolding component. The matrix-induced chondrogenesis uses a cell-free material that is placed in the cavity. Additionally, this material could be loaded with various growth factors or cytokines, enhancing repairing and differentiation of chondrocytes (Benthien and Behrens, 2011). Implantation of scaffolds with cells is more challenging but provides more promising results (Makris et al., 2015). To regenerate cartilage, a vast amount of biomaterials in the form of sponges, hydrogels, electrospun fibers, and microparticles have been produced, each of which has unique properties for the stimulation of chondrogenesis (Ahmed and Hincke, 2010; Vega et al., 2017). Although some of the implants produced so far show promising properties and the mere production of artificial cartilage was initially considered an easy goal by scientists, few of them were used to promote cartilage tissue regeneration in the clinic (Ge et al., 2012).

\section{ADVANTAGES AND DISADVANTAGES OF NANOCELLULOSE SCAFFOLDS}

Nanocellulose is the most abundant and renewable material on the planet. Its abundance and renewability, relatively low-cost, and relative ease of availability, among other characteristics, makes NC an excellent biomaterial for constructing scaffolds in cartilage tissue engineering. NC used as a biomaterial is divided into three categories, namely cellulose nanocrystals (CNCs), nanofibrillated cellulose (NFC), and bacterial nanocellulose (BNC). As a polymer composed of glucose subunits, nanocellulose has a wide range of tunable physical, chemical, and biological properties. Hydrophilicity, biocompatibility, and low immunogenicity are the most prominent attributes essential in cartilage TE (Chinta et al., 2021). In general, all types of NC are considered biocompatible since they are nontoxic, nonimmunogenic, noninflammatory, and facilitate cells to adhere, proliferate, migrate, and differentiate, either alone or in composites with other materials (Eslahi et al., 2019). However, toxicology studies on nanocellulose-based materials are still in the early stages. Many studies have shown that CNC can cause an inflammatory response, especially after chronic exposure via inhalation, with particle morphology and 
dimensions of CNCs being critical factors affecting the type of innate immune inflammatory responses (Stefaniak et al., 2014; Yanamala et al., 2014). Because of self-aggregation and bioaccumulation, inhaling a lot of $\mathrm{NC}$ might cause lung irritation. In vitro cytotoxicity studies of CNCs with various cell lines revealed no harmful effects at low doses $(\sim 50 \mu \mathrm{g} / \mathrm{ml})$, however high concentrations $(>\sim 100 \mu \mathrm{g} / \mathrm{ml})$ caused cell death and gene expression alterations in mammalian cells.

Cytotoxicity studies with NFCs revealed no indication of toxicity on the cell membrane or DNA proliferation (Jorfi and Foster, 2015). Also, in vitro and in vivo investigations of BNC revealed no cytotoxicity. BNC did not cause any DNA damage, apoptosis, or necrosis in cells. It seems that BNC is the most biocompatible among all NC types. By introducing alternative chemical groups on nanocellulose's surface, the proinflammatory reaction can be considerably reduced or switched into an anti-inflammatory effect. What is more, NC was shown to promote tolerogenic dendritic cells with the ability to generate several regulatory T cell subsets (Čolić et al., 2020). The long-term subcutaneous implantation of BNC did not demonstrate any signs of immunogenicity, inflammation, or formation of exudates around the implant, confirming that $\mathrm{BNC}$ does not induce the foreign body reaction and acts as an inert substance (Helenius et al., 2006). Not only 2D but also 3D BNC did not interfere with wound haemostasis in vivo and evoked a modest acute inflammatory reaction, neither a foreign body nor chronic inflammatory response, according to in vivo investigations (Osorio et al., 2019). Regarding NC biocomopatibility, there are also numerous contradictory results, which are most likely due to differences in the primary source of NC, its preparation, structure and shape, fiber length, contamination with endotoxin and glucans, applied concentrations, cell culture models, and a variety of other factors (Chinta et al., 2021).

The potential cytotoxicity of NC may be affected by its physicochemical properties, such as functionalization with specific chemical groups, as reviewed by Čolić et al. (Čolić et al., 2020). The possibility of surface modification, which in other nanostructures is not easy, is possible due to the presence of numerous hydroxyl groups, which provide the option of modification and exploiting chemical reaction strategies (Tortorella et al., 2020).

The great potential of nanocellulose in cartilage tissue engineering also lies in its large surface area and a high volume ratio allowing for adsorption of a wide range of atoms, ions, and molecules. Along with nanocellulose's hydrophilic hydroxyl moieties, the cell adhesion mechanism enables cells to adhere to cellulose. A large number of hydroxyl groups is also responsible for its water uptake capacity. However, because of high intermolecular and intramolecular hydrogen bonding of free hydroxyl groups, water solubility of NC is limited. Functional derivatization of the $\mathrm{OH}$ groups significantly improved the water solubility of cellulose derivatives such as methylcellulose, ethylcellulose, or hydroxypropyl cellulose (Medronho et al., 2012).

Nanocellulose also provides a high potential due to its excellent mechanical features. The crystalline regions increase cellulose's stiffness and strength, while the amorphous portions offer flexibility. Nanofibers are highly stiff (even $220 \mathrm{GPa}$ of the elastic modulus) and possess a high tensile strength of $\sim 10 \mathrm{GPa}$. What is more, the mechanical strength of NC can be is further increased by developing its composites with materials such as ceramics, nanoparticles, and polymers. Furthermore, the mechanical strength of $\mathrm{NC}$ can be increased by incorporating mechanically strong reinforcement materials such as ceramics, nanoparticles, and polymers into its composites (Khan et al., 2021). In addition, nanocellulose can be designed to fabricate products with desired shape structural complexity (Martínez Ávila et al., 2016).

Despite their many advantages, the small pore size is a significant drawback of NC, preventing the infiltration of mammalian cells deep into its matrix. The pore size can be modulated to meet the desired features for cartilage tissue engineering applications. NC needs to be also modified due to the lack of active sites that are required for cell signaling (Chinta et al., 2021).

Also, non-degradability is a crucial factor. A variety of fabrication techniques have been used to overcome these limitations, including electrospinning, photolithography, salt leaching, polymer blending, solvent casting, or a combination of nanofibers and microfibers, to create scaffolds with increased pore size and interconnectivity, which promote cellular migration/infiltration (Chinta et al., 2021).

\section{HYALINE CARTILAGE-COMPONENTS AND CHONDROGENESIS}

Cartilage is a specialized connective tissue present in several areas of the body. Hyaline cartilage, usually existing within joints, is the most widespread and is responsible for transferring and relieving stress between one bone and the other. Due to the high elasticity of the cartilage, the deformations caused by the loads transferred during the movements of the joints are reversible. Cartilage and synovial fluid form a layer of several millimeters, which significantly reduces the friction between the moving elements. Due to its density, cartilage, unlike most tissues, is not penetrated by blood and lymph vessels or nerves. Chondrocytes, therefore, usually function under low oxygen tension, and nutrients reach the cells via the synovial fluid (Eschweiler et al., 2021).

The cartilage extracellular matrix consists of water $(60-80 \%$ of total weight), collagen proteins ( $60 \%$ dry weight), and proteoglycan aggregates (30\% dry weight). Other substances such as lipids, phospholipids, non-collagen proteins and other glycoproteins are the remainder (Sophia Fox et al., 2009). Type II collagen is the most abundant isoform in articular cartilage, which accounts for over $80 \%$ of all collagens and, together with aggrecan, is considered a marker of differentiated chondrocytes. This isoform confers resistance to compressive forces in cartilage. Thus, its role in maintaining ECM homeostasis is critical, and loss causes perturbations in cartilage's physical and mechanical properties, leading to osteoarthritis. The remaining isoforms include collagen type IX and XI (3-15\%) and other types 


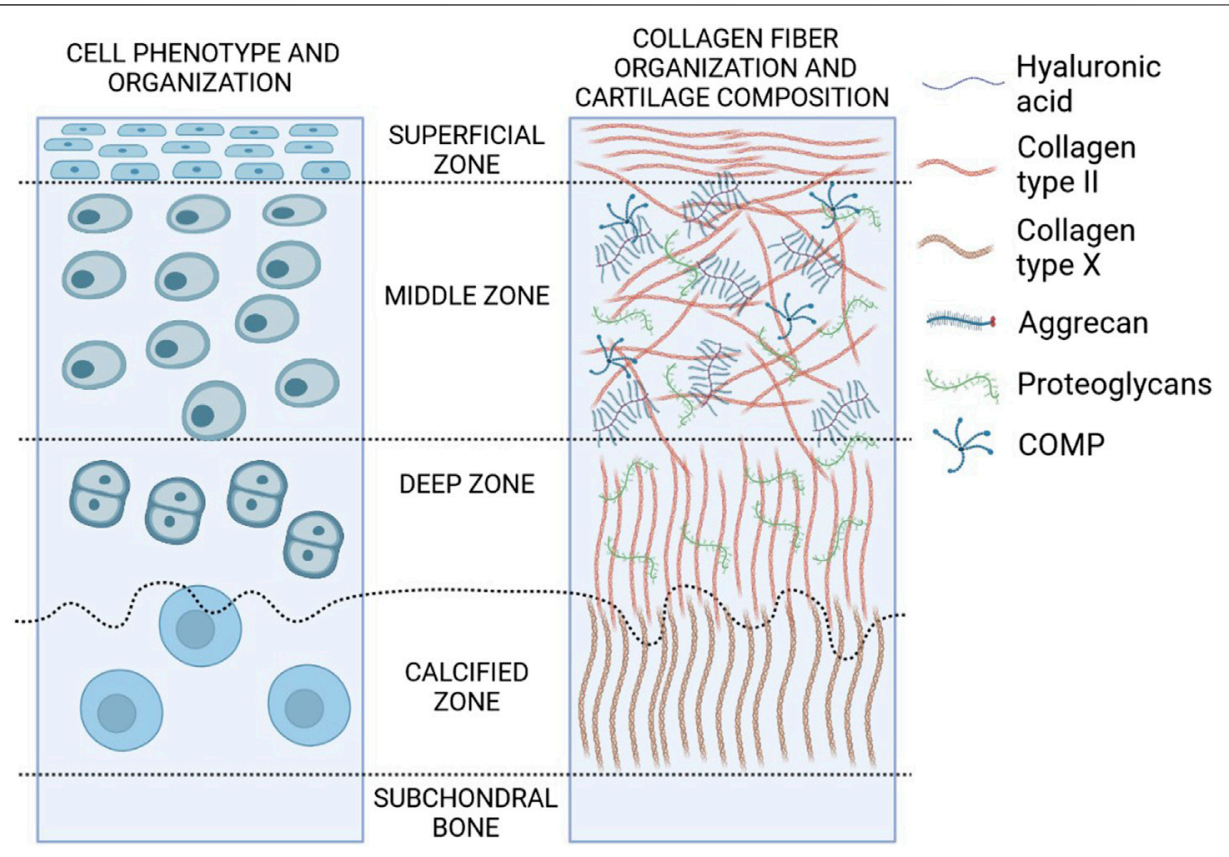

FIGURE 2 | Structure and composition of hyaline cartilage. Zones of hyaline cartilage with varying cellular distribution, shape, collagen organization, and biochemical markers are depicted in this diagram (created in BioRender.com).

(III, VI, X, XII, XIV). Type IX and XI collagens are responsible for the organization and structure of fibers (Sophia Fox et al., 2009; Demoor et al., 2014). Proteoglycans are the second largest group of macromolecules in the ECM of the articular cartilage. They consist of a core protein with one or more covalently attached linear glycosaminoglycan (GAG) chains. Aggrecan, a cartilagespecific proteoglycan, interacts with GAGs and hyaluronan to provide the cartilage its compressive resistance and shockabsorbing capacity under loading. Sulfonated GAG (sGAG) chains, such as chondroitin sulfate, keratan, and dermatan sulfate, are responsible for the ability to store a significant amount of water, ensuring flexibility and viscoelasticity (Demoor et al., 2014). As the adult articular cartilage is avascular, the ECM components with growth factors and cytokines play a crucial role in regulating chondrocyte metabolism and phenotype (Peng et al., 2021).

Various chemical factors, such as soluble growth factors or chemokines, have been shown to affect differentiation of mesenchymal stem cells (MSCs) into chondrocytes. In particular, transforming growth factor $\beta$ (TGF- $\beta$ ), bone morphogenetic protein (BMP), fibroblast growth factor (FGF), and insulin-like growth factor (IGF) have been demonstrated to induce chondrogenesis in many studies (Augustyniak et al., 2015). Also, small nonprotein molecules, such as a heterocyclic-structured kartogenin (KGN), can induce MSC differentiation into chondrocytes by activating JNK/RUNX1 pathways and suppression of $\beta$-catenin/RUNX2 signaling pathways (Jing et al., 2019). Furthermore, by modulating the transcription factor core binding factor beta subunit (CBFB)RUNX1 signaling, KGN binds filamin A triggering cartilage development.
Mature hyaline cartilage is structurally and functionally heterogeneous and organized in four distinct areas based on the cell shape, mutual position, and metabolic activity (Figure 2). The first superficial zone (up to $10-20 \%$ of the cartilage thickness) contains small fibroblast-like cells and numerous collagen fibers (primarily type II and IX collagen) packed tightly and aligned parallel to the articular surface. This arrangement ensures high tensile strength, necessary in the presence of stress under joint loads. An intermediate zone below (20-70\% of the thickness) with chondrocytes, spherical and irregularly distributed, contains proteoglycans and thicker collagen fibrils. The radial zone (up to $70-100 \%$ of the thickness) contains chondrocytes arranged in groups perpendicular to the articular surface, the largest diameter collagen fibrils in a radial disposition, the highest proteoglycan content, and the lowest water concentration. Finally, the calcified zone anchors the collagen fibrils of the deep area to subchondral bone. In this zone the cell population is scarce and chondrocytes are hypertrophic (Ge et al., 2012).

Cartilage is formed during chondrogenesis in the early phase of embryonic skeletogenesis with condensation of mesenchymal stem cells, which express mainly type I, III, and V collagens, and chondroprogenitor cell differentiation (Figure 3). Interactions between progenitors and ECM lead to differentiation into chondrocytes and synthesis of cartilage-specific ECM components such as collagen type IIB, IX, XI, and aggrecan. The hypertrophic process begins when chondrocytes enlarge and ECM is enriched in type $\mathrm{X}$ collagen. SOX9 (SRY-Box Transcription Factor 9) and RUNX2 (Runt-related transcription factor 2) are two transcriptional regulators essential for articular cartilage formation and hypertrophic maturation, respectively. SOX9 binds to chondrocyte-specific 
enhancer elements of cartilage matrix genes, including COL2A1, COL11A2, ACAN encoding collagen type II a 1 chain; collagen type XI a 2 chain and aggrecan, respectively. In chondrocytes, COL10A1, and MMP13, encoding collagen type $\mathrm{X}$ a 1 chain and matrix metalloprotease 13 - markers of chondrocyte hypertrophy and maturation are direct target genes of RUNX2. Additionally, chondrogenesis is regulated by the interplay of TGF- $\beta$, FGF, BMP, and WNT signaling pathways (Goldring, 2012).

\section{CELL SOURCES IN CARTILAGE TISSUE ENGINEERING}

Chondrocytes, the main cellular component of cartilage, form a small percentage $(1-10 \%)$ of the total volume of cartilage. Therefore, those cells do not exhibit cell-cell contacts. Additionally, mature chondrocytes lack mitotic activity and have a low metabolism that aims to maintain a balance between anabolism and catabolism processes, resulting in ECM components turnover. Collagen type II, aggrecan, and SOX9 are commonly expressed in normal and healthy chondrocytes in their native $3 \mathrm{D}$ environment. On the other hand, hypertrophic chondrocytes have a high level of collagen type $\mathrm{X}$, while dedifferentiated chondrocytes synthesize collagen type I. Gelsolin and TGF- $\beta 3$ secretion are increased in osteoarthritic chondrocytes (Brose et al., 2015).

The majority of cartilage regenerative medicine approaches rely on the implantation of highly differentiated chondrocytes. However, due to limited sources and complex harvesting methods, expansion of isolated cells in vitro is needed to obtain sufficient cellular material before re-implantation. This is done in a two-dimensional (2D) setting, where cells dedifferentiate and lose their natural phenotype, resulting in formation of fibroelastic cartilage that contains more collagen type I rather than collagen type II or undergo hypertrophy. Other potential shortcomings of autologous chondrocytes include donor site morbidity and poor capability for intrinsic repair. In addition, changes in the structure of the F-actin cytoskeleton, which also regulates cell mechanical properties, are linked to the loss of chondrocyte phenotype (Darling et al., 2009). Gene (mainly COL1A1, COL2A1, COL10A1, ACAN, SOX9, RUNX2, $A L P, V E G F, M M P 13$ ) and protein expression (aggrecan, type I and II collagens), ECM composition (GAG), and cell morphology have been used to determine the differentiation status of isolated chondrocytes. As dedifferentiation progresses, GAGs, COL2A1, SOX9, and ACAN lose their expression (Chen et al., 2015). Notably, the isolated chondrocytes can re-differentiate when inserted into a 3D environment. Chondrocytes are embedded in agarose, alginate beads, polymer gels or compressed into scaffold-free pellets by centrifugation to create $3 \mathrm{D}$ cultures. Additionally, using specific medium supplements (e.g., ascorbic acid, TGF isoforms, insulin, transferrin, selenite, and others) may support redifferentiation. Consequently, it is essential to develop scaffolds that can be fabricated into porous structures that allow cells to enter the $3 \mathrm{D}$ system and stimulate them to return to their differentiated state, where articular cartilage is generated (Caron et al., 2012).

Besides differentiated chondrocytes, cartilage tissue engineering uses chondrogenic progenitors. A pool of undifferentiated progenitor cells with high regenerative potential, limitless division capacity, self-renewal capability, simple accessibility, and hypoimmunogenicity would be ideal source to replace chondrocytes. Various stem cell sources have been studied, including bone marrow, adipose tissue, synovia, umbilical cord blood, periosteum, dental pulp, placenta, and embryos. The use of multipotent mesenchymal stem cells, which have the ability to differentiate into chondrocytes when given the right environmental factors, is an effective and safe way

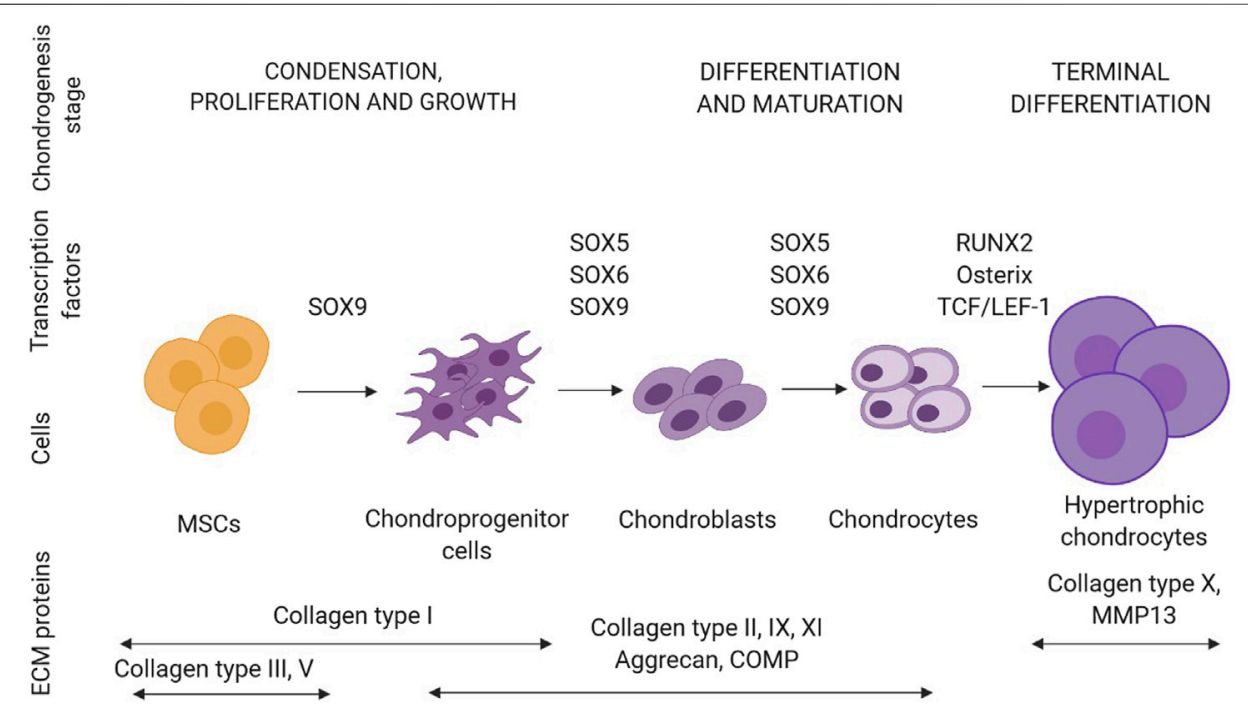

FIGURE 3 | Schematic representation of a sequence of events leading to the differentiation of mesenchymal stem cells (MSCs) towards chondrocytes (created in BioRender.com). In each stage of chondrogenesis, the temporal expression profiles of ECM proteins and transcription factors are highlighted. Abbreviations: COMP, cartilage oligomeric protein. 
to facilitate chondrogenesis. MSCs should meet the following basic requirements, according to the International Society for Cellular Therapy: adherence to the plastic surface when cultured in standard 2D conditions, expression of CD105, CD73, and CD90 but not CD45, CD34, CD14 or CD11b, CD79, or CD19 and HLA (human leukocyte antigen) class II, the capability of in vitro differentiation into osteoblasts, chondroblasts, or adipocytes (Dominici et al., 2006). Bone marrow (BM-MSCs) and stem cells from adipose tissue (ATSCs) are the most commonly used sources of human adult MSCs (Brose et al., 2015). The capacity of MSCs to differentiate into chondrocytes varies, with synovial MSCs showing the most significant potential to differentiate into articular chondrocytes (Zha et al., 2021). For allogenenic mesenchymal stem cell therapy, the umbilical cord may be an appealing source. Wharton's Jelly, a gelatinous tissue surrounding umbilical vessels, is used to separate umbilical cord MSCs (UCMSCs). Compared to the gold standard BM-MSCs, they have numerous advantages. Umbilical cords are readily available discarded tissues and the harvesting process is noninvasive. The doubling time of UC-MSCs is at least twice shorter because their properties are located between embryonic stem cells (ESCs) and adult MSCs. Furthermore, long-term in vitro culture seems to have little effect on their phenotype or genetic stability and does not induce tumorigenesis. UC-MSCs do not express hematopoietic markers such as CD34 and CD45 and are much more capable for chondrogenic differentiation than BMMSCs (Mebarki et al., 2021).

Unlike mature chondrocytes, MSCs can be expanded ex vivo to yield large numbers of cells, making them a plentiful cell source for autologous cell therapies. Unfortunately, obtaining a pure population of stem cells and precisely controlling the path of MSC differentiation is difficult. Besides, during chondrogenic induction, MSCs appear to develop hypertrophic properties, indicating the possibility of further differentiation toward endochondral bone formation (Arora et al., 2017). To overcome these limitations, cocultures of isolated MSCs and mature chondrocytes were employed to mimic physiological differentiation and regeneration processes. Cocultures tend to be more effective than monocultures, including paracrine interactions between both populations through direct or indirect contact, increased chondrogenic differentiation of stem cell populations, reduced levels of hypertrophy, and facilitated in vivo cartilage regeneration (Cho et al., 2018). Furthermore, when chondrocytes were cocultured with MSCs, they were able to maintain a healthy mature phenotype with lower expression of hypertrophic and fibrotic markers (Maumus et al., 2013).

Many of the problems listed above could be solved using induced pluripotent stem cells (iPSCs). In terms of pluripotency, phenotype, and proliferation potential, iPSCs resemble ESCs. However, iPSCs are isolated from a patient's somatic cells, avoiding the ethical concerns associated with the use of ESCs. The expression of genes related to stemness, such as the combination of OCT4, SOX2, KLF4, C-MYC and OCT4, SOX2, NANOG, and LIN28, is needed for the development of iPSCs (Wuputra et al., 2020). Several studies have successfully demonstrated the ability of iPSCs to differentiate into chondrocytes in the presence of the culture media containing growth factors such as TGF- $\beta$, FGF, BMP, and WNT. Now, major chondrogenic differentiation approaches of iPSCs include developing MSC-like iPSCs following differentiation into chondrocytes, the process of embryoid body formation, and cocultures of iPSCs-derived MSCs with primary chondrocytes (Csobonyeiova et al., 2021). However, until now, complete reprogramming and differentiation process of iPSCs into chondrocytes still take a long time. Besides, transplanting incorrectly reprogrammed iPSCs carries the risk of tumor formation (Wuputra et al., 2020).

\section{SOURCES OF NANOCELLULOSE FOR CARTILAGE ENGINEERING}

Many natural materials have been used to provide a satisfactory bioactive environment and mechanical support to promote the growth of new chondral tissue due to their superior biocompatibility, biodegradability, minimal negative immunological effect, and favorable cellular interaction. When natural polymers are inserted in vivo, they exhibit structural compatibility to biological molecules found in animals, minimizing the probability of an immune response. As a result, opposed to synthetic polymers, these materials are either non-immunogenic or have low immunogenicity (Chinta et al., 2021). Examples of natural polymers used in TE for cartilage regeneration include chitosan, collagen, alginate, silk fibroin, hyaluronan, gelatin, and cellulose (Figure 1).

Cellulose, a linear polysaccharide composed of d-glucopyranose units connected by $\beta-1,4$ glycosidic bonds, is the most abundant, sustainable, and renewable material. Cellulose is synthesized by plants, algae, some animals (e.g., tunicates), fungi, and bacteria. Among the bacteria, Komagataeibacter, Pseudomonas, Agrobacterium, and Sarcina can synthesize BNC from glucose and other carbon sources. The reinforcement segments in cellulosic fibrils in plants, algae, and bacteria are made up of highly organized (crystalline) and disordered (amorphous) microfibrillar motifs in an alternating arrangement (Figure 4). This typical configuration gives cellulose its essential mechanical behavior, with the amorphous motifs providing flexibility and plasticity and the crystalline motifs providing the strength and elasticity. The geometry of the arrays of cellulose synthases that assemble them determines the thickness and structure of cellulose microfibrils (Dutta et al., 2019).

The biosynthesis mechanisms of a plant (CNC and NFC) and bacterial (BNC) NC varies significantly. The top-down approach, in which chemical/mechanical breakdown methods disrupt the lignocellulosic biomass, is commonly used to synthesize plant cellulose from wood, cotton, hemp, potato tubers, and algae. Plant $\mathrm{NC}$ is manufactured from natural cellulosic materials using processes that preserve much of the cellulose microfibrils' native structure. Native cellulose fibers are commonly found in the plant cell wall as a quasi-solid, cohesive framework. The diameter of cellulose microfibrils in higher plants is typically about $3 \mathrm{~nm}$ and the microfibrils are aggregated into bundles that are $10-20 \mathrm{~nm}$ thick (Jarvis, 2018). NFC, usually produced by delamination of wood pulp 

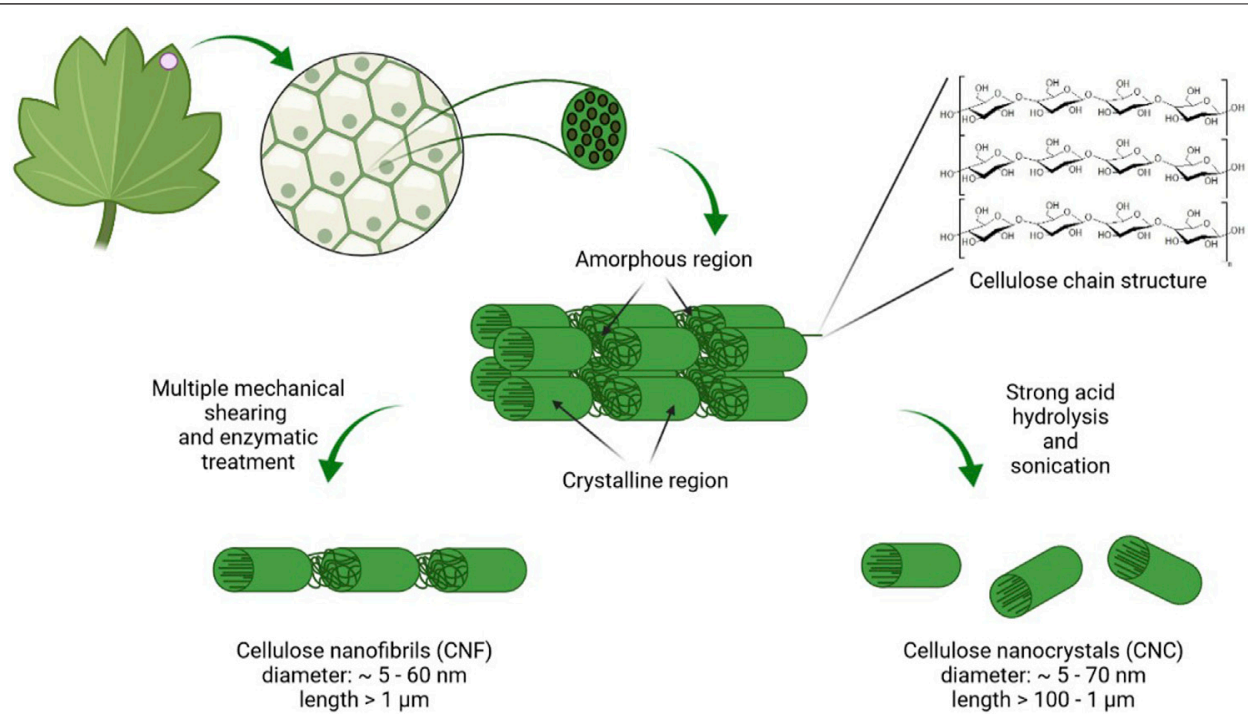

FIGURE 4 | Scheme of plant nanocellulose origin, composition, and organization. Cellulose in plant cells wall is organized into micro- and macrofibrilles. During the purification process lignin and hemicellulose are removed. Acid hydrolysis leads to formation of highly crystalline CNC while NFC is prepared by disintegration with high shear forces (created in BioRender.com).

by mechanical pressure before and/or after chemical or enzymatic treatment, contains microfibrils with a diameter of 5-60 $\mathrm{nm}$ and length of several micrometers. CNC, also known as whiskers, contains rodlike cellulose crystals with widths and lengths ranging from 5 to 70 and $100 \mathrm{~nm}$ to several micrometers, respectively. Acid hydrolysis is used to remove amorphous portions of a purified cellulose source, accompanied by ultrasonic treatment (Klemm et al., 2011).

BNC pellicles are produced biotechnologically using a variety of bacteria (including Komagataeibacter) as an exopolysaccharide at an air-tight interface under static culture conditions (Mahendiran et al., 2021). The bacteria's cellulose fibrils, joined to form ribbons and then a 3D nanofiber network (fiber diameter below100 nm). The hydrogels of BNC possess up to $99 \%$ water. BNC was found to be very pure with a high $\mathrm{Mw}$ (weight-average molecular weight), high crystallinity, and good mechanical stability. The biofabrication method opens up the exciting possibility of producing cellulose through fermentation and controlling the shape and the structure of the nanofiber network during biosynthesis (Klemm et al., 2011).

The physical properties of nanocellulose are determined by three hydroxyl groups at the C-2, C-3, and C-6 positions. Due to the presence of reactive surfaces with $\mathrm{OH}$ group various derivatives can be fabricated by introducing functional groups using chemical, mechanical, and/or enzymatic methods. The presence of three hydroxyl groups per repeating unit also makes NC a strong candidate for initiating chondrogenesis because the presence of $\mathrm{OH}$ groups on a biomaterial's surface has been shown to promote stem cell chondrogenic differentiation (Curran et al., 2005). Therefore, there are many examples of NC-based scaffolds inducing stem cells to differentiate into chondrocyte phenotypes and then promoting the development of cartilage tissue (e.g., Taokaew et al., 2014; Chen et al., 2018; Talaat et al., 2020).

Nanocellulose used in cartilage TE is available in different formats like hydrogels, membrane-like structures, porous membranes, electrospun fibers, porous scaffolds, and bioinks (Tables 1-3). Hydrogels are the most widely used biopolymers in cartilage engineering because of their highly swollen $3 \mathrm{D}$ environment, which is very similar to soft tissues and allows for the diffusion of nutrients, growth factors, and cellular waste through the elastic network. A hydrogel is a soft material made up of a porous $3 \mathrm{D}$ network of crosslinked polymer chains that can hold up to $99.9 \%$ water. 3D hydrogels, unlike standard 2D culture, allow chondrocytes to preserve their shape and phenotype while providing a physiological environment in which they can form cartilage tissue. The gelatinous and flexible 3D scaffold is necessary to sustain cell growth and mimic the niche observed in vivo. Hydrogels were first used in orthopedic applications for the less invasive treatment of localized cartilage defects via injection or arthroscopy (Liu et al., 2017). Hydrogels that mimic the properties of ECM have shown high potential as tissue engineering scaffolds and injectable hydrogels. Mixing therapeutic and bioactive signaling agents and cells with precursor solutions is a simple way to introduce them into scaffolds (Aswathy et al., 2020). Nanocellulose-based hydrogels can be made from bacterial and plant NC, such as CNC, NFC, and BNC, and cellulose derivatives such as methylcellulose (MC), carboxymethylcellulose (CMC), and hydroxypropylmethylcellulose (HPMC). Physical crosslinking in the presence of triggers (temperature, ions, $\mathrm{pH}$ ) or chemical cross-linking (free radical polymerization, Michael-type addition, Schiff's base reaction, enzymatic cross-linking, etc.) are used to create a cellulose-based hydrogel by in situ gelation (Balakrishnan et al., 2013). 


\section{PLANT-DERIVED NC-BASED SCAFFOLDS FOR CARTILAGE TISSUE ENGINEERING}

The use of NFC to improve the physical properties of hydrogels has sparked a lot of interest in recent years. NFC is the smallest fibrous component of cellulose fibers with diameters ranging from 5 to $60 \mathrm{~nm}$ depending on the origin. NFC has been deemed a top choice for various applications in the material science industry due to its abundance, high surface area, water retention value, transparency, and sustainability. Compared to $\mathrm{CNC}, \mathrm{NFC}$ has a higher aspect ratio and can form robust physical entanglements and networks in composites. These characteristics make the gels far more durable than when the network is created solely by weak hydrogen bonds between water and fibrils. Additionally, NFC has a substantially lower Youngs modulus in tension (around $30 \mathrm{GPa}$ ) than $\mathrm{CNC}$, which varies depending on the delamination procedure (Tanpichai et al., 2012). The biocompatible, injectable, mechanically stable, and slowly degradable NFC/chitosan (CS) thermosensitive hydrogel was shown to be ideal for cartilage regeneration. When CS and $\beta$-glycerophosphate (GP) are combined in aqueous solution, stimulus-responsive in situ forming gels are formed due to a combination of $\mathrm{pH}$ - and temperature-dependent interactions. However, the use of CS/GP hydrogels is limited due to poor mechanical strength, rapid deterioration, and loss of spatial support, whereas combining NC and CS has been shown to increase the latter's biocompatibility, biodegradation, and mechanical characteristics. The chondrogenesis ability of human dental pulp stem and progenitor cells (hDPSCs) embedded in NFC/CS/GP hydrogel was validated by histological and immunohistochemical studies as well as gene expression, suggesting that NFC/CS/GP composite hydrogels can serve as a promising stem cell-based cartilage repair approach that is minimally invasive. In vivo studies demonstrated that $3 \mathrm{D}$ cell NFC/CS/GP constructs elicited an immunological response that had a favorable impact on the scaffold microenvironment. The immune response manifested itself as an acute inflammatory reaction which attracted macrophages. Macrophages together with hDPSCs secreted cytokines and growth factors necessary for the regeneraton of injured tissue (Talaat et al., 2020).

A combination of crosslinked sodium alginate and NC for cartilage tissue engineering has been investigated thoroughly. Sodium alginate offers structural stability in these composite hydrogels through chemical crosslinking, which aids in transforming the hydrogel into a solid substance. Calcium ions (crosslinker) can be added to sodium alginate to replace the sodium ions, forming strong bonds between alginate chains. The concentration of a crosslinker controls characteristics of the hydrogel by adjusting the structural and mechanical properties of the solid material (Lin et al., 2011). It was shown that increased $\mathrm{CaCl}_{2}$ concentration changes the overall architecture, pore size, and porosity. $\mathrm{CaCl}_{2}$ concentration appeared to impact $\mathrm{CNC}$ more than other NC types (NFC or a blend of CNC and NFC). Depending on the NC form, the hydrogels had $34-50 \%$ porosity with average pore diameters ranging from 0.22 to $0.91 \mu \mathrm{m}$ (Al-Sabah et al., 2019).
Because of the low cytotoxicity and structural similarity with ECM, NFC with alginate in the form of hydrogels attracts attention in bioink formulation for $3 \mathrm{D}$ printing. $3 \mathrm{D}$ printing is a promising field that aspires to generate functional tissue-like constructs with precision and adaptability for tissue/organ regeneration replacement. $3 \mathrm{D}$ printing is an additive manufacturing technique in which a layer-by-layer computercontrolled deposition process creates $3 \mathrm{D}$ models. Construction of biological structures with tissue-specific geometry is now possible thanks to 3D printing and its ability to mimic the heterogeneous and complicated native tissues. This method allows hydrogels to be dispensed in three dimensions with increasing precision and resolution. Cells are enclosed in a uniform density and quantity within the printed gel in contrast to standard two-step methods involving inoculating cells into pre-fabricated scaffolds. Cell distribution is often diverse in the latter approach and the biomaterial may not be fully colonized. 3D printing is classified into numerous types based on the operating mechanism, the raw material, the energy sources, and the biological tasks. Inkjet-based, laser-based, and extrusion-based printing are the three basic techniques used to classify $3 \mathrm{D}$ printing. Extrusion printing is the most extensively used procedure in TE for producing cell-laden hydrogels, owing to its well-known benefits such as a low cost, ease of software or hardware upgrades, and excellent cellular viability (Martínez Ávila et al., 2016; Curvello et al., 2019).

So far, no proof of pure NC hydrogels being used for 3D bioprinting has been found. Shear thinning is much improved when NC is combined with other polymers such as alginate. Alginate increases gel viscosity by acting as a crosslinker. It strengthens the scaffold and ensures that the shape is maintained throughout the procedure. Because of its excellent printing accuracy, which can be attributed to its dominant elastic behavior, $\mathrm{NC}$ as a primary component in a bioink might improve shape fidelity. The addition of NC to bioinks in concentrations ranging from 2 to $10 \%$ provides better shear thinning, mechanical strength, and water retention (Toit et al., 2020). Gatenholm et al., for the first time, proposed NC for producing implants and scaffolds for tissue engineering applications utilizing inkjet printing in 2010 (Gatenholm et al., 2010).

Markstedt et al. developed a biobased ink comprised of crosslinked 2.5\% (w/v) NFC, $10-40 \%$ alginate, and $\mathrm{CaCl}_{2}$. NFC, produced from the bleached sulfite softwood cellulose pulp consisting of $40 \%$ pine (Pinus sylvestris) and $60 \%$ spruce (Picea abies) by combined refining, enzymatic treatment, and high-pressure homogenization, was mixed with alginate $(150-250 \mathrm{kDa})$. They tested NFC/alginate compositions (90/10, $80 / 20,70 / 30,60 / 40 \mathrm{w} / \mathrm{v} \%$ ) and $80 / 20$ appeared to be the best ink formulation based on all the outcomes, including rheological characteristics, compressive stiffness, and shape deformation after ionic crosslinking with $\mathrm{Ca}^{2+}$. The ink exhibited good gelling during crosslinking and minimum shape deformation and was demonstrated to be a viable host for human nasoseptal chondrocytes (hNCs) that were encapsulated and 3D bioprinted into gridded constructs (Markstedt et al., 2015). 60/40 NFC/alginate composition with human induced 
TABLE 1 | Plant-derived NC applied to cartilage tissue engineering.

\begin{tabular}{|c|c|c|c|c|c|}
\hline $\begin{array}{l}\text { Plant NC } \\
\text { type }\end{array}$ & System & $\begin{array}{c}\text { Source of } \\
\text { chondrocytes or } \\
\text { stem cells } \\
\text { and experimental } \\
\text { design }\end{array}$ & Outcome & $\begin{array}{l}\text { Analyses related } \\
\text { to differentiation } \\
\text { and proliferation }\end{array}$ & Reference \\
\hline \multicolumn{6}{|l|}{ Hydrogels } \\
\hline Cellulose hydrogel & $\begin{array}{l}\text { Filter paper pulp dissolved in } \\
\text { heated } \mathrm{LiBr} \text {; microporous } \\
\text { scaffolds prepared with } \\
\text { dispersed } \mathrm{NaCl} \text { particles }\end{array}$ & Rabbit chondrocytes & $\begin{array}{l}\text { In vitro } \\
\text { Chondrocytes formed 3D } \\
\text { spheroid structures on the } \\
\text { surface of sponge-like } \\
\text { cellulose gel matrix }\end{array}$ & sGAGs & Isobe et al. (2018) \\
\hline $\begin{array}{l}\text { CNC/USPIO/SF } \\
\text { hydrogels }\end{array}$ & $\begin{array}{l}\text { Hydrogels prepared by mixing } \\
\text { CNC/USPIO with SF at room } \\
\text { temperature and lyophilization }\end{array}$ & $\begin{array}{l}\text { The hydrogels were } \\
\text { implanted in the cartilage } \\
\text { defects of adult rabbits for } 4 \text {, } \\
8 \text {, and } 12 \text { weeks }\end{array}$ & $\begin{array}{l}\text { In vitro } \\
\text { Proliferation of BM-MSCs } \\
\text { was not affected by USPIO } \\
\text { labeling. A spheroid shape } \\
\text { with ECM deposition was } \\
\text { observed. CNC/USPIO/SF } \\
\text { did not promote the } \\
\text { fibrocartilage phenotype } \\
\text { In vitro } \\
\text { There was no difference in } \\
\text { biocompatibility, } \\
\text { chondrogenesis, and } \\
\text { regeneration efficiency in the } \\
\text { groups implanted with non- } \\
\text { labeled or USPIO-labeled } \\
\text { BM-MSC-loaded hydrogels }\end{array}$ & $\begin{array}{l}\text { Cell viability, gene } \\
\text { expression (COL1A1, } \\
\text { SOX9, COL2A1, ACAN), } \\
\text { ferric irons, proteoglycans, } \\
\text { multiparametric MRI }\end{array}$ & Chen et al. (2018) \\
\hline $\begin{array}{l}\text { CNC/Dex/USPIO/ } \\
\text { KGN hydrogels }\end{array}$ & $\begin{array}{l}\text { CNC/Dex/USPIO/KGN } \\
\text { hydrogels prepared by } \\
\text { injecting the USPIO-KGN } \\
\text { solution into CNC/Dex } \\
\text { hydrogels followed by drying } \\
\text { at room temperature }\end{array}$ & $\begin{array}{l}\text { BM-MSCs were seeded on } \\
\text { the hydrogels for } 14 \text { days } \\
\text { The hydrogels were } \\
\text { implanted in the cartilage } \\
\text { defects created on the center } \\
\text { of the trochlear groove of } \\
\text { adult rabbits for } 6 \text { and } \\
12 \text { weeks }\end{array}$ & $\begin{array}{l}\text { In vitro } \\
\text { Higher proliferation, } \\
\text { differentiation and secreted } \\
\text { ECM on CNC/Dex/USPIO/ } \\
\text { KGN as compared to } \\
\text { hydrogels without KGN } \\
\text { In vivo } \\
\text { The CNC/Dex/USPIO-KGN } \\
\text { group had the best cartilage } \\
\text { regeneration and the defect } \\
\text { was mostly repaired after the } \\
\text { 6th week }\end{array}$ & $\begin{array}{l}\text { Cell proliferation and } \\
\text { viability, SEM, H\&E } \\
\text { staining, proteoglycans, } \\
\text { sGAGs, collagen I, II, gene } \\
\text { expression (SOX9, } \\
\text { COL1A1, COL2A1, ACAN) }\end{array}$ & Yang et al. (2019a) \\
\hline $\begin{array}{l}\text { CNC/collagen/ } \\
\text { USPIO/KGN } \\
\text { scaffolds }\end{array}$ & $\begin{array}{l}\text { Scaffolds prepared by } \\
\text { injecting the USPIO-KGN } \\
\text { solution into the collagen/ } \\
\text { CNC scaffolds followed by } \\
\text { lyophilization }\end{array}$ & $\begin{array}{l}\text { BM-MSCs were seeded on } \\
\text { the cylinder scaffold samples } \\
\text { and cultured up to } 14 \text { days }\end{array}$ & $\begin{array}{l}\text { In vitro } \\
\text { Scaffolds were } \\
\text { cytocompatible. High } \\
\text { expression of SOX9 and } \\
\text { COL1A1 could cause a } \\
\text { tendency to induce formation } \\
\text { of fibrotic cartilage instead of } \\
\text { hyaline cartilage. } \\
\text { Furthermore, a CNC- } \\
\text { enhanced collagen scaffold } \\
\text { with higher mechanical } \\
\text { properties could cause } \\
\text { mechanical stress damage in } \\
\text { vivo }\end{array}$ & $\begin{array}{l}\text { Cytotoxicity, cell viability, } \\
\text { SEM, proteoglycans, DNA } \\
\text { content, gene expression } \\
\text { (SOX9, COL1A1, COL2A1, } \\
\text { ACAN) }\end{array}$ & Yang et al. (2019b) \\
\hline $\begin{array}{l}\text { a-CNCs/collagen } \\
\text { hydrogel }\end{array}$ & $\begin{array}{l}\text { a-CNCs produced through } \\
\text { oxidation. aCNC/collagen } \\
\text { hydrogel crosslinked by Schiff } \\
\text { base bonds }\end{array}$ & $\begin{array}{l}\text { BM-MSCs from neonatal } \\
\text { rabbits were mixed with } \\
\text { a-CNC/collagen suspension } \\
\text { to prepare BM-MSC-loaded } \\
\text { discs } \\
\text { Hydrogels with BM-MSCs } \\
\text { were injected subcutaneously } \\
\text { to the mid-dorsal region of } \\
\text { nude mice for } 1 \text { and } 3 \text { days }\end{array}$ & $\begin{array}{l}\text { In vitro } \\
\text { BM-MSCs encapsulated in } \\
\text { the a-CNC/collagen hydrogel } \\
\text { showed high viability } \\
\text { In vivo } \\
\text { Subcutaneous injection } \\
\text { showed improved implant } \\
\text { integrity and higher cell } \\
\text { retention }\end{array}$ & $\begin{array}{l}\text { Cell viability, confocal } \\
\text { microscope, H\&E staining }\end{array}$ & Zhang et al. (2020) \\
\hline $\begin{array}{l}\text { PLA/S-CNC/P- } \\
\text { CNC multilayer } \\
\text { scaffold }\end{array}$ & $\begin{array}{l}\text { A porous multilayer scaffold } \\
\text { prepared by wetting the } \\
\text { surface of one of the layers }\end{array}$ & $\begin{array}{l}\text { Human fetal chondrocytes } \\
\text { were seeded on cylindrical } \\
\text { scaffolds ( } 8 \mathrm{~mm} \text { diameter and }\end{array}$ & $\begin{array}{l}\text { In vitro } \\
\text { The biocompatibility of the } \\
\text { three individual layers by }\end{array}$ & $\begin{array}{l}\text { Cell viability, cytoskeleton } \\
\text { imaging, LDH assay, the } \\
\text { protein content, }\end{array}$ & $\begin{array}{l}\text { Camarero-Espinosa } \\
\text { et al. (2016) }\end{array}$ \\
\hline
\end{tabular}

(Continued on following page) 
TABLE 1 | (Continued) Plant-derived NC applied to cartilage tissue engineering.

\begin{tabular}{|c|c|c|c|c|c|}
\hline $\begin{array}{l}\text { Plant NC } \\
\text { type }\end{array}$ & System & $\begin{array}{c}\text { Source of } \\
\text { chondrocytes or } \\
\text { stem cells } \\
\text { and experimental } \\
\text { design }\end{array}$ & Outcome & $\begin{array}{l}\text { Analyses related } \\
\text { to differentiation } \\
\text { and proliferation }\end{array}$ & Reference \\
\hline
\end{tabular}

with a dust-free tissue paper $\quad \sim 5 \mathrm{~mm}$ thickness) for 2 or impregnated with acetone 4 weeks or on non-porous and bring it into contact with a films PLA/S-CNC and PLA second layer

$\mathrm{CNC} /$ alginate, $\mathrm{NFC/alginate}$ NCB/alginate hydrogels

PCL/PAA/CNC hydrogel

NFC/CS/GP hydrogel

NFC/alginate $\quad$ CELLINK ${ }^{\circledR}$

bioink

NFC/alginate $\quad$ CELLINK ${ }^{\circledR}$
bioink

NFC, CNC and a blend (NCB) produced as an aqueous slurry from raw wood biomass with AVAP ${ }^{\circledR}$ technology and mixed with alginate

PCL/PAA/CNC fabricated through condensation and addition polymerization

NFC from hemp hurd added to GP/CS to form the hydrogel-forming solutions

hNCs were encapsulated in bioink formulation [80:20 NFC/alginate (w/w)] and 3D bioprinted cell-laden gridded constructs were analyzed

after day 1 and 7 of culture mixed with NFC/CS/GP and cultured for 21 days Chondrogenesis of hDPSCs was compared to BM-MSCs The hydrogel with embedded hDPSCs was injected subcutaneously into rats up to 21 days

\section{preparation and mixing}

anter 1 day

caused a decrease in viability). An increase in cell viability was detected in the printed constructs after

7 days of 3D culture compared to day 1

In vitro

hNCs and rabbit auricular chondrocytes (rACs) were mixed with NFC/alginate and cell-laden bioink was printed into auricular and lattice
The NFC/alginate increased redifferentiation, proliferation, viability proteoglycans, gene expression (COL1A1, COL2A1)

Cell viability

Al-Sabah et al. (2019)

Cell viability

Pourbashir et al. (2020)

Cell viability, $H \& E$, collagen

Talaat et al. (2020)

staining, gene expression (COL2A1, COL10A1,

ACAN)

Indirect cytotoxicity test,

Markstedt et al. (2015)

viability, proteoglycans,

mineralization, collagen I, II,

X; DNA, sGAGs, collagen

contents

Cytotoxicity, viability, cytoskeleton imaging,

Martínez Ávila et al. electron microscopy, DNA

GAG content, gelatine

zymography, gene expression (COL1A1,

(Continued on following page) 
TABLE 1 | (Continued) Plant-derived NC applied to cartilage tissue engineering.

\begin{tabular}{|c|c|c|c|c|c|}
\hline $\begin{array}{l}\text { Plant NC } \\
\text { type }\end{array}$ & System & $\begin{array}{c}\text { Source of } \\
\text { chondrocytes or } \\
\text { stem cells } \\
\text { and experimental } \\
\text { design }\end{array}$ & Outcome & $\begin{array}{l}\text { Analyses related } \\
\text { to differentiation } \\
\text { and proliferation }\end{array}$ & Reference \\
\hline
\end{tabular}

structures and cultured for up to 28 days

\section{NFC/alginate $\quad$ CELLINK $^{\circledR}$}

bioink

NFC/ $\quad$ CELLINK ${ }^{\circledR}$

alginate bioink

NFC/alginate $\quad$ CELLINK ${ }^{\circledR}$

bioink

\section{NFC/alginate $\quad$ CELLINK $^{\circledR}$}

bioink

\section{hBM-MSCs and/or}

hNCs were mixed with NFC/ alginate and cell-laden bioink was bioprinted as 3D gridded constructs. Constructs were implanted in a subcutaneous pocket on the back of the mice up to 60 days

hBM-MSCs and/or hNCs were mixed with NFC/alginate and bioprinted into the 3Dgrid constructs $(5 \times 5 \times$ $1.2 \mathrm{~mm}$ ); the printed constructs were then implanted into a subcutaneous pocket on the back of nude Balb/C mice up to 60 days

hBM-MSCs and hNCs with NFC/alginate were bioprinted into the $3 \mathrm{D}$ grid constructs $(10 \times 10 \times 1.2 \mathrm{~mm})$; Constructs were implanted into a subcutaneous pocket on the back of nude mice. After 45 days, a full-thickness skin allograft was transplanted onto the constructs and the construct enclosed subcutaneously. Group 1 was sacrificed on day 60 , whereas group 2 had their skin-bearing construct uncovered on day 60 and were sacrificed on day 75 hNCs and hBM-MSCs or hNCs and human SVF (stromal vascular fraction)derived stem cells from abdominal lipoaspirate mixed with NFC/alginate bioink were $3 \mathrm{D}$ bioprinted into $6 \mathrm{~mm} \times$

$6 \mathrm{~mm} \times 1.2 \mathrm{~mm}$ grid and

\section{In vivo}

The combination of NFC/ alginate, hNCs, and hBMMSCs for 3D bioprinting resulted in high-fidelity constructs with good mechanical properties and a gradual increase of GAGs.

The cocultured group showed a more pronounced cell proliferation and enhanced deposition of human collagen ॥

In vivo

Constructs consisting of hNCs showed good proliferative capacity and cartilage-cluster formation. In constructs comprising a mixture of chondrocytes and stem cells, an additional proliferative effect was observed involving GAGs and type II collagen synthesis. The density of GAG-positive cells in the mixed constructs was lower than in constructs with only chondrocytes

In vivo

The skin transplants integrated well with the 3D bioprinted constructs. A tight connection between the fibrous, vascularized capsule surrounding the 3D bioprinted constructs and the skin graft was observed. The skin grafts survived the uncovering and exposure to the environment

In vivo

The transplanted human chondrocytes proliferated in clusters with the formation of cartilage-like tissues. Over the 10-months, no adverse events were observed. SVFderived stem cells exerted
COL2A1, VCAN, RUNX2, SOX9, COMP, MATN3, RUNX2, ACAN ), H\&E,

COMP, collagen I, GAG, aggrecan, matrilin-3

staining

GAGs, collagens staining, Möller et al. (2017) collagen II, FISH

Proteoglycans, collagens,

Apelgren et al. (2017) collagen II, Ki-67 staining, $\mathrm{FISH}$

GAGs, collagens staining Apelgren et al. (2018)

GAGs, proteoglycans, the Apelgren et al. (2021) number of chondrocytes 
TABLE 1 | (Continued) Plant-derived NC applied to cartilage tissue engineering.

\begin{tabular}{|c|c|c|c|c|c|}
\hline $\begin{array}{l}\text { Plant NC } \\
\text { type }\end{array}$ & System & $\begin{array}{c}\text { Source of } \\
\text { chondrocytes or } \\
\text { stem cells } \\
\text { and experimental } \\
\text { design }\end{array}$ & Outcome & $\begin{array}{l}\text { Analyses related } \\
\text { to differentiation } \\
\text { and proliferation }\end{array}$ & Reference \\
\hline
\end{tabular}

implanted subcutaneously
the back of nude mice up to 10 months

NFC/alginate and NFC/HA bioinks
NFC/alginate sulfate bioink
$\mathrm{CNC} /$ alginate, $\mathrm{NFC/alginate,}$ $\mathrm{NCB} /$ alginate bioinks

\section{CNC-GelMA \\ HAMA \\ hydrogel ink}

CELLINK ${ }^{\circledR}$ or NFC was mixed with HA-based hydrogel
NFC was mixed with alginate sulfate
NFC, CNC and a blend (NCB) produced as an aqueous slurry from raw wood biomass with AVAP $^{\circledR}$ technology and mixed with alginate
CNCs were mixed with GelMA and HAMA and LAP as a photoinitiator to form the reinforced hydrogel ink
Chondrocytes isolated from human nasoseptal cartilage samples were mixed with NC/ alginate bioinks, 3D bioprinted into cylinder discs (5 mm diameter and $4 \mathrm{~mm}$ height) and cultured up to 3 weeks

ATDC5 cells were encapsulated in the optimal GelMA/HAMA ink containing $0.030 \%(\mathrm{w} / \mathrm{v})$ LAP and the hybrid printed constructs were fabricated. Cell viability was evaluated over 7 days

hBM-MSCs were seeded on composite nanofibrous discs [with and without fibronectin similar trophic effects on chondrocyte proliferation to those observed using hBMMSCs

In vitro

The NFC/HA bioink showed low proliferation of the limited cell population remaining in the construct after encapsulation and phenotypic changes away from pluripotency. NFC/ alginate (60/40, dry weight \% ratio) maintained a pluripotent phenotype after 3D bioprinting. After 5 weeks, hyaline-like cartilaginous tissue with collagen type II expression and lacking tumorigenic Oct4 expression was observed in NFC/ alginate

In vitro

Chondrocytes in NFC/ alginate sulfate gel discs were viable, mitogenic and synthesized collagen II. The printing conditions affected the behavior of the cells; however, with wide diameter, conical needles providing the best preservation of cell function

In vitro

NC was non-cytotoxic with no significant differences in cell viability post-printing with CNC, NFC and NCB. NCB/ alginate formulation was chosen for biocompatibility experiments, where increased viable chondrocytes and maintained a rounded chondrogenic phenotype after prolonged culture In vitro

The coaxial printing strategy allowed the generation of $3 D$ structures where cells were encapsulated in the core and protected by the shell comprising the crosslinked form of GeIMA/HAMA ink. Cells remained viable

In vitro hBM-MSCs maintained similar viability and cell binding with and without FN
H\&E, GAGs, collagens,

Nguyen et al. (2017) proteoglycans, collagen II, Oct4 staining, gene expression (ACAN, SOX9, COL2A1), cytoskeleton imaging, two-photon excitation fluorescence and second-harmonic

generation

Cell viability, cytoskeleton Müller et al. (2017) imaging, collagen I, II, proteoglycan hyaluronic acid-binding region staining

Cell viability, LDH release, Jessop et al. (2019) SEM, compression testing

Cell viability, adhesion, Begum et al. (2020) gene expression (COL1A1, COL2A1, ACAN, SOX9, ratio) was electrospun into nanofibers without post-spun
ALPL, PPARG), 
TABLE 1 | (Continued) Plant-derived NC applied to cartilage tissue engineering.

\begin{tabular}{|c|c|c|c|c|c|}
\hline $\begin{array}{l}\text { Plant NC } \\
\text { type }\end{array}$ & System & $\begin{array}{c}\text { Source of } \\
\text { chondrocytes or } \\
\text { stem cells } \\
\text { and experimental } \\
\text { design }\end{array}$ & Outcome & $\begin{array}{l}\text { Analyses related } \\
\text { to differentiation } \\
\text { and proliferation }\end{array}$ & Reference \\
\hline
\end{tabular}

treatment, using a

trifluoroacetic acid and acetic to 2 weeks

acid cosolvent system
Membranes/other scaffolds

Paper cellulose membrane

CaP-coated cellulose

NFC/PEGDA aerogels

Cellulose/silk membranes
Cellulose membrane chamber from a silicone tube $(21 \mathrm{~mm} \times$ $15 \mathrm{~mm} \times 10 \mathrm{~mm}$, outer diameter $\times$ inner diameter $\times$ height) and cellulose nanopore-size membrane (in vivo bioreactor (IVB)

Regenerated cellulose II monofilament fibres were activated in a saturated $\mathrm{Ca}(\mathrm{OH})_{2}$ solution and coated with $(\mathrm{CaP})$ carbonated apatite
Human fetal cartilage progenitor cells (hFCPCs) were placed into the IVB and implanted under back skins of rabbits

1 week cultured engineered cartilage tissue from IVB was then implanted into a cartilage defect created in the trochlear groove of the femur of adult rabbits up to 12 weeks

Chondrocytes isolated from the articular cartilage of bovine calves cultured up to 6 weeks
A mixture of NFC and PEGDA used to prepare aerogels with a multiscale pore structure through a combination of stereolithography and freezedrying

Blends of wood pulp cellulose and silk were prepared using a ionic liquid (1-ethyl-3 methylimidazolium acetate) as a solvent
NFC/starch composites
NFC extracted from the rice straw with chemo-mechanical method was combined with starch by a combination of film casting, salt leaching, and freeze-drying methods
Mouse BM-MSCs were seeded on aerogel scaffolds and cultured for 21 days

hBM-MSCs were seeded on fibronectin-coated materials cellulose/silk circular discs and cultured up to 2 weeks

Chondrocytes isolated from articular cartilage were cultured on NFC/starch scaffolds up to 7 days
. All chondrogenic genes were upregulated without addition of TGF- $\beta$. Cells cultured on the composite substrate showed a lesser cell stretch with diffuse paxillin staining, demonstrating the hMSC response to the elasticity of this surface. The chondroinduction did not involve the main chondrogenic differentiation signaling pathway (Smad2/3 regulated phosphorylation via TGF- $\beta$ )

In vivo

The IVB promoted the synthesis of cartilage matrix and maintained the cartilage phenotype and delayed calcification. The protein, glucose, and HA contents in the IVB bioreactor fluid were closer to synovial fluid than serum

The IVB promoted better healing of the cartilage defect In vitro

CaP-coated cellulose was

the suitable material in terms of chondrocyte adhesion and cartilage development (vitality of the adhered chondrocytes was excellent but collagen I and II expression was comparable on untreated as well as o $\mathrm{CaP}$-coated scaffolds)

In vitro

Honeycomb structure of the scaffold affected the proliferation of mBMSCs and secretion of proteoglycans

In vitro hBM-MSCs growing on a blend combination of cellulose and silk in a 75:25 ratio upregulated the expression of chondrogenic marker genes in the absence of TGF- $\beta$. No adipogenic or osteogenic differentiation was detected

In vitro

NFC/starch porous scaffolds with interconnected pores supported attachment and growth of chondrocytes cytoskeleton imaging paxillin, aggrecan, collagen II staining, chondrogenic signaling

Cell viability, H\&E staining, Li et al. (2020) proteoglycans, DNA,

sGAG, collagen contents, mineralization, collagen I,

II, $X$

Cell viability, Müller et al. (2006) proteoglycans, collagen I, II

Cell viability, SEM, H\&E, $\quad$ Tang et al. (2021) proteoglycans, GAGs

Cell adhesion and viability, Singh et al. (2013) gene expression (ACAN,

SOX9, COL1A1, COL2A1), triglicerides, collagen II staining

Cell viability, SEM

Nasri-Nasrabadi et al (2014) 
pluripotent stem cells has shown promising results to stimulate cartilage formation as well (Nguyen et al., 2017).

CELLINK AB (Gothenburg, Sweden) sells a bioink containing NFC/alginate $(2 / 0.5 \mathrm{w} / \mathrm{w} \%)$ under the CELLINK ${ }^{\circledast}$ trademark. On a commercial level, CELLINK ${ }^{\circledast}$ offers various ready-to-use bioinks for a variety of tissue engineering applications. CELLINK $^{\circledR}$ has a high level of consistency, printability and compatibility with a wide range of cell types. This bioink series has been extensively examined in both in vitro and in vivo research. It was shown to support chondrocyte proliferation and differentiation with excellent viability and cartilage ECM formation. CELLINK ${ }^{\circledR}$ was used to bioprint human nasal chondrocyte-laden patient-specific auricular constructions with an open inner structure and good shape fidelity. hNCs proliferated and underwent chondrogenesis, resulting in the formation of cartilage-specific ECM components (Martínez Ávila et al., 2016). Additionally, 3D bioprinted constructs were produced using CELLINK $^{\circledR}$ with hBM-MSCs alone (Apelgren et al., 2017; Möller et al., 2017) or with hBM-MSCs in combination along with hNCs (Apelgren et al., 2017; Möller et al., 2017; Apelgren et al., 2018). A further proliferative impact involving chondrocyte synthesis of GAGs and type II collagen was reported in constructions containing a mixture of chondrocytes and stem cells (Möller et al., 2017).

The long-term (10-months study) outcomes on chondrogenesis associated with transplanted 3D-bioprinted CELLINK $^{\circledast}$ demonstated no adverse events, such as ossification, neoplasms, or necrosis (Apelgren et al., 2021). Also, a sulfated version of alginate that can bind FGF, TGF, and hepatocyte growth factors (HGF) was combined with NFC to form a printable bioink with better chondrogenic characteristics compared to inertia alginate-containing bioinks (Müller et al., 2017).

CNC can also be used in nanocomposite bioinks because of its intrinsic features like high mechanical strength, good biocompatibility, high surface area, and simplicity of surface modification. Depending on the source, the crystalline percentage can range from 50 to $90 \%$. The elastic moduli of the CNCs were determined to be around 105-168 GPa (Kuhnt and Camarero-Espinosa, 2021). Due to reversible hydrogen bonding, CNCs were introduced in covalently crosslinked hydrogels to improve mechanical strength and provide viscoelastic behavior. Mainly, alginate mixed with $\mathrm{CNC}$ as an additive has emerged as a promising bioink for fabricating artificial tissues (Jessop et al., 2019). Besides, to increase the mechanical properties of the structures, a hybrid bioink was created by mixing CNCs and a gelatin methacryloyl/ hyaluronic acid methacrylate (GelMA/HAMA) solution. CNCGelMA/HAMA was used as the structural component and GelMA/HAMA as the cytogel containing ATDC5 cells. GelMA is a photoreactive gelatin derivative possessing ArgGly-Asp tripeptide that promotes cellular attachment, spreading, and differentiation, as well as matrix metalloproteinase sequences (Kurian et al., 2021). The reinforced bioinks demonstrated good printability, shearthinning characteristics, structural support and structural integration in $3 \mathrm{D}$ bioprinted constructions. Meantime, the soft bioinks in the GelMA/HAMA mixture offered a favorable milieu for cell multiplication. As a result, ATDC5, a mouse chondrogenic cell line, stayed alive during the bioprinting process (Fan et al., 2020).

To improve the mechanical properties, CNC was also introduced into polycaprolactone (PCL)/poly (acrylic acid) (PAA) hydrogel. PCL, a biodegradable and biocompatible polyester approved by the Food and Drug Administration, has gained a lot of scientific interest as an implanted biomaterial. Despite having the essential toughness and mechanical qualities, PCL is hydrophobic, resulting in insufficient cell attachment. Semi-interpenetrating polymer networks (semi-IPNs) were incorporated to restore the system's hydrophilicity to address this problem. Semi-IPNs are composite polymeric materials made by synthesizing or crosslinking a polymer network in the presence of non-crosslinked polymers. When PCL is combined with hydrophilic polymers, it can provide excellent hydrophilicity while maintaining mechanical strength. Therefore, PCL and CNC were caught in a network of acrylic acid. The mechanical qualities of artificial cartilage were improved using an optimal amount of CNC, which was $0.5 \%$. The semi-IPNs' biocompatibility was proven by testing viability and cell attachment (Pourbashir et al., 2020).

Surface-modified CNCs have also been examined as green and biocompatible collagen hydrogel reinforcing agents. Compared to $\mathrm{CNC/collagen} \mathrm{hydrogels} \mathrm{without} \mathrm{Schiff} \mathrm{base} \mathrm{links,} \mathrm{a} \mathrm{nanocomposite}$ aldehyde-functionalized $\mathrm{CNC} \quad(\mathrm{a}-\mathrm{CNC}) /$ collagen hydrogel crosslinked by dynamic Schiff base bonds displayed quick shearthinning, self-healing, and enhanced elastic modulus. After extrusion in vitro, BM-MSCs encapsulated in the a-CNC/collagen hydrogel showed good cell viability. MSCs encapsulated in the a-CNC/collagen hydrogel and injected subcutaneously demonstrated better implant integrity and cell retention. In vivo subcutaneous injection showed that a-CNCs/collagen hydrogel acted as a protective biomaterial of BM-MSCs by minimally invasive procedures. Therefore, the hydrogel would not only protect cells during injection, but also fit into the cartilage defect, making MSC delivery for cartilage regeneration a viable option (Zhang et al., 2020).

Sulfated CNC (S-CNC) was employed to create a porous multilayer scaffold made up of an anisotropic poly (d,l-lactide) (PLA) superficial layer with tubular pores oriented parallel to the subchondral bone, an isotropic middle layer made up of PLA and sulfated CNCs, and a deep anisotropic layer made up of PLA and phosphated CNC (P-CNC) with tubular pores oriented orthogonal to the subchondral bone. These scaffolds spatially controlled the morphology, orientation, and differentiation of human chondrocytes. The constructs enabled the growth of tissue with characteristics similar to the natural equivalent and encouraged localized hydroxyapatite production to allow integration with the subchondral bone (Camarero-Espinosa et al., 2016).

Another interesting approach with CNC-based hydrogels provides a new methodology to non-invasively monitor biomaterial behavior after implantation. The ability to image hydrogels is helpful for both confirming that the hydrogel was successfully delivered to the target region and monitoring the erosion of the hydrogel over time. Chen et al. developed a functional, visualizable ultrasmall superparamagnetic 
iron oxide (USPIO)-labeled natural hydrogel system for semiquantitative monitoring of cartilage deterioration and revealed hyaline cartilage regeneration using multiparametric magnetic resonance imaging (MRI). A silk fibroin (SF) was introduced into the $\mathrm{CNC}$ scaffold forming $\mathrm{CNC} / \mathrm{SF}$ blend hydrogel to improve cartilage regeneration. MRI showed that the USPIO-labeled hydrogel had enough contrast to track the degradation process. As a result, this approach gives helpful information for noninvasive monitoring and therapeutic efficacy of implanted hydrogels (Chen et al., 2018). Yang et al. also created a type of USPIO-based hydrogel for cartilage regeneration that encouraged the differentiation of BM-MSCs into chondrocytes by mixing USPIO-KGN with CNC/Dex (dextran). KGN was discovered to be produced over an extended period, attracting endogenous host cells and encouraging BM-MSC differentiation into chondrocytes for efficient cartilage regeneration, as evidenced by both in vitro and in vivo investigations (Yang et al., 2019a).

Finding suitable solvents is the most challenging part of preparing NC-based hydrogels since $\mathrm{NC}$ is insoluble in water and forms a colloidal suspension. Therefore, many chemical processes and modifications have been established to dissolve cellulose in water or organic solvents. Recently, a novel class of cellulose solvent, aqueous lithium bromide ( $\mathrm{LiBr}$ ) was used to form cellulose hydrogels with various shapes from a rigid cylinder to soft sponges from ashless filter paper pulp. Additionally, $\mathrm{NaCl}$ particles were distributed in cellulose solution. Finally, all $\mathrm{NaCl}$ particles were rinsed out following gelation, resulting in a soft sponge-like cellulose hydrogel structure with micro-pores of about $300 \mu \mathrm{m}$ in diameter connected by $100-\mu \mathrm{m}$ pores. Rabbit chondrocytes proliferated and differentiated into cartilage tissue when seeded on such a hydrogel (Isobe et al., 2018).

To sum up, plant-derived NC holds promise for cartilage tissue engineering. Plant NC-based nanomaterials can be produced in the form of CNFs or CNCs. Chemical, enzymatic, and mechanical treatments, as well as the combination of these methods, can be applied to produce NC with desired properties. The surface of CNF and CNC with functional groups allow their use for the implementation of cross-linking chemistry in the hydrogel (Xu et al., 2018). An overview of plant-based scaffolds used for studies on cartilage tissue engineering with chondrocytes and stem cells is listed in Table $\mathbf{1}$.

\section{CELLULOSE DERIVATIVES AS SCAFFOLDS FOR CARTILAGE TISSUE ENGINEERING}

The most important cellulose derivatives, cellulose ethers and esters, have been commercially available for many years. Cellulose ethers made by replacing the hydroxyl groups in cellulose with methyl, hydroxyethyl, hydroxypropyl, and other similar groups are soluble in alkaline aqueous phases and several organic solvents. The esterification of cellulose allows it to be processed into various forms, including solutions, fibers, and 3D structures. Cellulose acetate, cellulose acetate propionate, cellulose acetate butyrate, and other cellulose esters are widely used (Seddiqi et al., 2021). Physical and chemical crosslinking has been utilized to build cellulose-based hydrogels from MC, CMC, HPMC, hydroxypropyl cellulose (HPC), or cellulose acetate (CA) (Table 2; Figure 5).
The cellulose ether CMC is the most widely used. Enzymatically crosslinked injectable hydrogel consisting of CMC, sulfated CMC (sCMC), gelatin was prepared for delivery of a combination of caprine articular chondrocytes (ACs) and infrapatellar fat pad derived mesenchymal stem cells (IFP-MSCs) to a cartilage lesion site to induce chondrogenesis (Arora et al., 2017). Oxidized CMC/gelatin (Balakrishnan et al., 2013) and amidic derivative of CMC (CMCA) hydrogels are also examples of injectable, biodegradable and ECM mimicking hydrogels supporting growth and differentiation of chondrocytes that integrate well inside the cartilage defect area, stabilizing and preventing further deterioration (Leone et al., 2008).

MC, categorized as a lower critical solution temperature polymer because of its unique ability to generate thermoreversible hydrogels when heated, was used to create polyurethane (PU)/MC composite scaffolds. In a custom-built bioreactor, PU/MC composites with hBM-MSCs were subjected to a mix of compression and shear pressures. Mechanical stimulation increased chondrogenic gene expression while histological investigation revealed sulfated GAGs and collagen II only in loaded specimens, indicating that MC hydrogels are suitable for load-induced MSC chondrogenesis. The use of MC as a thickening additive for alginate extrusion-based $3 \mathrm{D}$ printing is a new technique (Schütz et al., 2017) showing great promise in the bioplotting of several cell types, including chondrocytes and MSCs (Gonzalez-Fernandez et al., 2019; Hodder et al., 2019). MC was also employed to create hierarchical scaffolds to reproduce the zonal organization of articular cartilage. Encapsulated cells underwent redifferentiation. The presence of a mineralized zone supported chondrogenic ECM production by altering the ionic concentrations of calcium and phosphorus (Kilian et al., 2020).

Silanized-hydroxypropyl methylcellulose (Si-HPMC) is a more complex cellulose derivative used to fabricate hydrogel scaffold materials in cartilage tissue engineering to promote the proliferation and differentiation of cells. In a crosslinking procedure involving the condensation of silanol groups, SiHPMC is steam sterilizable, injectable, and self-sets at physiological $\mathrm{pH}$. This method of crosslinking without the use of an exogenous reticulating agent is typically associated with high biocompatibility. Once reticulated, this cellulose-based hydrogel has only $2 \%$ dry polymer and $98 \%$ water, closely mimicking the high hydration of articular cartilage ECM. Although Si-HPMC's mechanical properties (compressive modulus approximately $2.9 \mathrm{kPa}$ ) differ from those of articular cartilage (around $30 \mathrm{kPa}$ ), it provides a 3D environment in which cells can proliferate and create cartilage ECM (Rederstorff et al., 2017). Si-HPMC is a self-crosslinking hydrogel used for the $3 \mathrm{D}$ culture of chondrocytes and MSC (Vinatier et al., 2005; Vinatier et al., 2009; Merceron et al., 2011). It has also been preclinically investigated to repair stiffer tissues like cartilage, with less promising results (Vinatier et al., 2007). Also, composite of SiHPMC with nano-reinforcement clay known as laponites (Boyer et al., 2018), GY785 (a high-molecular weight marine exopolysaccharide) or and Si-chitosan (Boyer et al., 2020) were synthesized and demonstrated to be helpful in treating cartilage 
TABLE 2 | Cellulose derivatives applied to cartilage tissue engineering.

\begin{tabular}{|c|c|c|c|c|c|}
\hline $\begin{array}{l}\text { Cellulose } \\
\text { derivative } \\
\text { type }\end{array}$ & System & $\begin{array}{c}\text { Source of } \\
\text { chondrocytes or } \\
\text { stem cells } \\
\text { and experimental } \\
\text { design }\end{array}$ & Outcome & $\begin{array}{l}\text { Analyses related } \\
\text { to differentiation } \\
\text { and proliferation }\end{array}$ & Reference \\
\hline
\end{tabular}

\section{Hydrogels}

$\mathrm{CMC} / \mathrm{sCMC} /$

gelatin

hydrogels
CMC, SCMC, and gelatin conjugated with tyramine groups with $\mathrm{N}-$ (3ethylcarbodiimide/ $\mathrm{N}$-hydroxysuccinimide dimethylaminopropyl)- $\mathrm{N}^{\prime}-$
A combination of caprine ACs and IFP-MSCs were encapsulated in the hydrogels and cultured for up to 28 days
Oxidized CMC/gelatin hydrogel

CMCA hydrogel
Borate-diol complexation of oxidized CMC (dialdehyde derivative CDA) with borax followed by Schiff's reaction of CDA's aldehyde groups with the amino groups of gelatin led to the formation of a rapidly in situ gelling hydrogel

CMCA obtained by converting a large percentage of carboxylic groups ( $50 \%)$ of CMC into amidic groups
PU/MC

hydrogel composites
A thermo-reversible hydrogel composed of $\mathrm{MC}$ in a $\mathrm{Na}_{2} \mathrm{SO}_{4}$ solution obtained by dispersion technique
Si-HPMC hydrogel
Si-HPMC was synthesized by grafting 3-glycidoxypropyltrimethoxysilane on HPMC in heterogeneous medium
Murine articular chondrocytes were seeded on the hydrogel and culture for $24 \mathrm{~h}$ or encapsulated and incubated 4 weeks A defect was made in a goat patella and filled with hydrogel

Chondrocytes from the human knee articular cartilage were mixed with the hydrogel and cultured for up to 14 days The hydrogels were implanted in the cartilage defects of adult rabbits.

The treatments were repeated every 10 days for 30 or 50 days hBM-MSCs in a hydrogel were filled into cylindrical $(8 \mathrm{~mm}$ diameter $\times 4 \mathrm{~mm}$ height) porous $\mathrm{PU}$ scaffolds (pore size of 90-300 $\mu \mathrm{m})$, transferred into a pin-on-ball bioreactor system and subjected to 21 loading cycles

$1 \mathrm{~cm}$ diameter specimens of the hydrogel were subcutaneously implanted into the dorsa skin of mice for 3 and 6 weeks

\section{Rabbit articular}

chondrocytes (shoulders, knee, and femoral heads) and human chondrocyte SW1353 and C28/L2 cell lines $3 \mathrm{D}$ cultured in $\mathrm{Si}-$ HPMC hydrogel

Human NCs were allowed to attach in wells of culture plates. After $24 \mathrm{~h}$, Si-
In vitro

The encapsulated TGF- $\beta 1$ was shown to be bioactive and supported better cell survival over control hydrogels. The TGF loaded hydrogels demonstrated good sulfated GAG and expression and deposition of hyaline cartilage markers and reduced the deposition of fibrocartilage and hypertrophy markers

In vitro

Hydrogels revealed porous structure with ROS generation

In vivo

The hydrogel integrated well with host cartilage tissue.

Chondrocytes existed in clusters migrated through the scaffold and maintained GAG deposition In vitro

CMCA supported growth,

differentiation, and the synthesis of ECM components. CMCA hydrogel did not stimulate the release of MMP1 and MMP13 In vivo

CMCA stimulated cartilage healing

In vitro

Mechanical stimulation led to a significant increase in chondrogenic gene expression, while histological analysis detected SGAGs and collagen ॥ only in loaded specimens In vivo

The lack of any hydrogel-derived immunoreaction was demonstrated

Si-HPMC had no adverse effects on chondrocyte viability and proliferation. Chondrocytes retained viability, developed nodular structures, produced GAGs and expressed chondrocyte markers

In vitro

hydrogel
Si-HPMC had no adverse effects on hNC viability and proliferation.
Cell viability, membrane Arora et al. (2017) permeabilization, cytoskeleton imaging, proteoglycans, GAGs, DNA and collagen content, collagen I, II, X staining

Cytoskeleton imaging,

Balakrishnan et al. GAGs, DNA content, (2013)

proteoglycans, collagen II staining, ROS generation

Cell viability, collagen II, Leone et al. (2008) C-propeptide, aggrecan, IL-1 $\beta$, MMP-

1, MMP-13, proteoglycans, cathepsin B

Gene expression

Cochis et al. (2017) (COL1A1, COL2A1 ACAN, SOX9, COL10A1), ALP activity, sGAGs, proteoglycans, collagen I, II, X

Cell viability, Vinatier et al. (2005) proliferation, gene expression (COL1A, COL1A2, ACAN), sGAGs

Cell viability, Vinatier et al. (2007) proliferation, gene expression (COL1A, 
TABLE 2 | (Continued) Cellulose derivatives applied to cartilage tissue engineering

\begin{tabular}{|c|c|c|}
\hline $\begin{array}{l}\text { Cellulose } \\
\text { derivative } \\
\text { type }\end{array}$ & System & $\begin{array}{c}\text { Source of } \\
\text { chondrocytes or } \\
\text { stem cells } \\
\text { and experimental } \\
\text { design }\end{array}$ \\
\hline
\end{tabular}

HPMC was added to

Si-HPMC

hydrogel

Si-HPMC

GY785 was mixed with Si-HPMC to with GY785 prepare composite hydrogels

Si-HPMC Laponites mixed with Si-HPMC to hydrogel with prepare composite hydrogels laponites

Si-HPMC Hydrogels obtained by mixing of Siwith Si-
HPMC with Si-chitosan hASCs or canine ACSs each well for 1, 2, and 3 days. Chondrocytes were also mixed with SiHPMC for 3D culture for 3 weeks hNCs in SiHPMC hydrogel were implanted subcutaneously in the back along each side of nude mice for 3 weeks

hNCs produced GAGs, developed nodular structures and expressed chondrocyte

markers

In vivo

After implantation, a cartilaginous tissue exhibiting a nodular structure containing GAGs and type II collagen was formed. Chondrocytes were positively stained with $\mathrm{Ki}-67$ antibodies In vitro

Dedifferentiated rabbit

NCs were mixed with SiHPMC for 3D culture for 3 weeks

Si-HPMC hydrogels with NCs were implanted in the cartilage defects created on the center of the femoral trochlea of adult rabbits for 6 weeks

Human ATSCs or freshly isolated horse NCs were mixed with Si-HPMC and implanted in subcutaneous pockets of nude mice for 5 weeks Human ATSCs or horse NCs were mixed with SiHPMC and cultured in the presence of

chondrogenic or control medium for 28 days or implanted in subcutaneous pockets of nude mice for 5 weeks Rabbit ACs attached to wells of culture plates and HPMC/GY785 were added for 1,2 , and 3 days Freshly isolated or dedifferentiated ACs were mixed with Si-HPMC/ GY785 for 3D culture for 3 weeks

Constructs of ACs with SiHPMC/GY785 were implanted into subcutaneous pockets of nude mice for 3 weeks Subcutaneous implantation of hNCs in conjunction with SiHPMC/1\% laponites in the back along each side of nude mice for 6 weeks attached to the surface of culture plates. After $24 \mathrm{~h}$

NCs in 3D exhibited a highe expression of type II collagen and of collagen I than the 2D cultures In vivo of GAG, type II collagen and displaying a specific organization resembling native articular cartilage was formed

In vivo

The capability of ATSCs to give rise to cartilage when implanted with Si-HPMC hydrogel was

shown. Horse NCs served as a positive control

In vitro

Si-HPMC supported

chondrogenic differentiation of ATSCs. 3D pellet culture, but not 2D conditions, in chondrogenic medium supported GAGs and collagen II production In vivo hATSCs formed nodules with cartilaginous features In vitro

GY785 did not affect ACs viability and proliferation

Si-HPMC/GY785 hydrogels supported a differentiated chondrocyte-like phenotype In vivo

Si-HPMC/GY785 constructs transplanted into nude mice revealed the production of a cartilage-like ECM containing high amounts of GAGs and collagen II

In vivo

The composite hydrogel and entrapped hNCs formed a cartilage-like tissue with ECM containing GAG and collagens

In vitro

\section{Analyses related to differentiation and proliferation}

Reference aggrecan and lower expression

A tissue exhibiting the production
COL1A2, ACAN), sGAGs, proteoglycans, H\&E staining, collagen fibers, Ki67, collagen II

Gene expression (COL1A, COL1A2, ACAN), sGAGs, H\&E staining, collagen II

GAGs, type II collagen Merceron et al. (2010)

GAGs, type II collagen, Merceron et al. (2011) gene expression

(COL1A, COL1A2, $A C A N, C O M P)$

Cell viability, Rederstorff et al. proliferation, GAGs, collagen I, II, aggrecan staining, gene expression (COL1A, COL1A2, ACAN)

H\&E staining, sGAGs, Boyer et al. (2018) proteoglycans

Cell viability, GAGs, Boyer et al. (2020) $H \& E$ staining, proteoglycan, collagen,

(Continued on following page) proteoglycans, 
TABLE 2 | (Continued) Cellulose derivatives applied to cartilage tissue engineering

\begin{tabular}{|c|c|c|c|c|c|}
\hline $\begin{array}{l}\text { Cellulose } \\
\text { derivative } \\
\text { type }\end{array}$ & System & $\begin{array}{c}\text { Source of } \\
\text { chondrocytes or } \\
\text { stem cells } \\
\text { and experimental } \\
\text { design }\end{array}$ & Outcome & $\begin{array}{l}\text { Analyses related } \\
\text { to differentiation } \\
\text { and proliferation }\end{array}$ & Reference \\
\hline
\end{tabular}

chitosan

hydrogels

poly $\quad$ N-isopropylacrylamide (NIPAAm)

(NIPAAm)- $\quad$ grafted to MC with ammonium

$g$-MC persulfate as initiator and $\mathrm{N}, \mathrm{N}, \mathrm{N}^{\prime}, \mathrm{N}^{\prime}$ -

copolymer tetramethylethylenediamine as an

hydrogel accelerator

HEC/CS/GP Chitosan-GP was mixed with HEC hydrogel

HEC/CS/GP Chitosan-GP was mixed with HEC hydrogel hydrogel was added up to 7 days. Chondrocytes were also mixed with hydrogel for 3D culture for 7 days. Hydrogel with hASC was implanted into subcutaneous pockets of nude mice for 6 weeks and with canine ASC in the osteochondral defects of dogs for 4 months ATDC5 cells were encapsulated at high cell density within the hydrogel and cultured for up to 28 days

A chondral defect was created in the trochlear groove or medial femoral sheep condyle and calf chondrocytes mixed with HEC/CS/GP stained with calcein AM were injected into the spaces between the osteochondral grafts. Articular chondrocyte nuclei were labeled by immersing the entire mosaic arthroplasty with Hoechst 33,342

In live sheep, a fullthickness unilateral defect was created in the medial femoral condyle

Chondrocytes isolated from sheep articular cartilage of knee joint were mixed with HEC/CS/GP hydrogel and cultured for 3 weeks or transplanted to the defects created in the knee for 12 and 24 weeks

HEC/CS/GP A chitosan and chitosan-GP solutions hydrogel were prepared separately

SF formed a presolution that could MA bioink create a $\beta$-sheet; HPMC modified with methacrylate (MA) that could crosslink
hBM-MSCs and rat BMMSCs (rBM-MSCs) were resuspended in HEC, mixed with CS-GP and cultured up to 28 days BM-MSCs were mixed with SF/HPMC/MA to print ring shape scaffolds with a diameter of $8 \mathrm{~mm}$, 8 layers, under UV radiation, followed by incubation to promote the formation of $\beta$-sheet structure
The addition of Si-chitosan to SiHPMC did not significantly alter the viability of 3D cultured hASCs In vivo

In the canine osteochondral defect model, while the empty defects were only partially filled with a fibrous tissue, defects filled with hydrogel with or without ASCs, revealed a significant osteochondral regeneration In vitro

PNIPAAm-g-MC did not affect the cell viability and proliferation and augmented the synthesis of GAGs with round-shaped morphology

Ex vivo and in vivo

$\mathrm{HEC/CS/GP} \mathrm{loaded} \mathrm{with} \mathrm{viable}$ chondrocytes formed an adhesive seal with ex vivo mosaic arthroplasty defects from sheep knee joints. In mosaic arthroplasty defects of live sheep, bleeding occurred beneath part of the hydrogel carrier, and the gel was cleared after 1 month in vivo

In vitro

Chondrocytes in the hydrogels retained normal growth and accumulated pericellular sGAGs and type II collagen

In vivo

Defected part of the cartilage was completely repaired with hyaline cartilage tissue within 24 weeks, even in the case of implantation of hydrogels without chondrocytes In vitro

HEC/CS/GP supported cell survival and proliferation of MSCs and differentiation towards

cartilage-like tissue

In vitro

BM-MSCs could survive and proliferate in the printed scaffold. Combining with growth factors, the genes further upregulated after chondrogenic differentiation elastin, muscle, mucin and fibrin, collagen I, II staining

Cell viability, Sá-Lima et al. (2011) proliferation, H\&E, proteoglycan, GAGs

Fluorescent microscopy

Hoemann et al. (2007)

Cell viability, H\&E,

Hao et al. (2010) proteoglycan, GAGs, collagen II staining

Viability, proliferation, H\&E, GAGs,

Naderi-Meshkin et al. proteoglycans staining

(2014)

\section{Cell viability, gene Ni et al. (2020)} ACAN, SOX9)

(


TABLE 2 | (Continued) Cellulose derivatives applied to cartilage tissue engineering

\begin{tabular}{|c|c|c|c|c|c|}
\hline $\begin{array}{l}\text { Cellulose } \\
\text { derivative } \\
\text { type }\end{array}$ & System & $\begin{array}{c}\text { Source of } \\
\text { chondrocytes or } \\
\text { stem cells } \\
\text { and experimental } \\
\text { design }\end{array}$ & Outcome & $\begin{array}{l}\text { Analyses related } \\
\text { to differentiation } \\
\text { and proliferation }\end{array}$ & Reference \\
\hline
\end{tabular}

bioink $\quad$ with autoclave, supercritical $\mathrm{CO}_{2}$ $\left(\mathrm{ScCO}_{2}\right), \mathrm{UV}$, and $\gamma$ irradiation

MC/alginate Bioinks contained plasmids encoding

bioink for RALA-pLUC or BMP2 or ca ombination of TGF- $\beta 3$, BMP, 2 and SOX9 within networks of 3D printed fibers

MC/alginate/ Alginate mixed with $\mathrm{MC}$, halloysite HNT/PVDF nanotube (HNT) and polyvinylidene bioink fluoride (PVDF)

MC/alginate bioink combined with CPC

Alginate mixed with $\mathrm{MC}$ was used to create a biphasic scaffolds with calcium phosphate cement (CPC) gorming hydroxyapatite
MC/alginate bioink Alginate mixed with $\mathrm{MC}$ to create biphasic

combined with $\mathrm{CPC}$

Scaffolds with CPC
osteoarthritic patients
Bovine primary
chondrocytes (BPCs) isolated from metacarpal phalangeal joints were mixed with MC/alginate, bioprinted as a $3 \mathrm{D}$ constructs $(9.5 \mathrm{~mm} \times$ $9.5 \mathrm{~mm} \times 1.4 \mathrm{~mm}$ per layer) and cultured up to 21 days

Porcine BM-MSCs were encapsulated in $\mathrm{MC}$ / alginate bioink or 3D bioprinted to form cylindrical constructs and cultured for 4 weeks Acellular or MSC laden bioinks were used to print cylindrical dis, cs which were then implanted subcutaneously in nude mice up to 21 days

Human chondrocytes were seeded on 3D printed scaffolds and cultured up to $96 \mathrm{~h}$

hTERT-MSC cell line was mixed with bioink and $3 D$ bioprinted into cuboid scaffolds $(12 \mathrm{~mm} \times$ $12 \mathrm{~mm} \times 1 \mathrm{~mm}$ ) with an alternating layer pattern (orientation of strands $0 \%$ $90^{\circ}$ ) and cultured up to 21 days

\section{In vitro}

Concerning cell survival and

proteoglycan production, the rradiation and autoclaving were the best candidates for sterilization. The $\mathrm{ScCO}_{2}$ treatment of $\mathrm{MC}$ resulted in an unfavourunfavorablesponse

In vitro and in vivo

MC/alginate bioinks enabled the accelerated release of non-viral vector-pDNA complexes and enhanced the transfection of encapsulated MSCs. When used to deliver an appropriate combination of chondrogenic genes (pTGF-pBMP-pSOX9) to MSCs, these pore-forming bioinks were able to support robust and stable chondrogenesis of MSCs

In vitro

Cells attached, spread, and formed a polygonal structure with filopodia and were homogeneously distributed throughout the scaffold within the pores. By increasing the HNT in composition, living cell efficiency increased

In vitro

No change of viability within the MC/alginate strands of biphasic scaffolds was detected. Cells survived and proliferated along the CPC surface. Cells after migration to the CPC surface exhibited a spread, elongated morphology whereas cells inside shape

In vitro

Human chondrocytes from articular cartilage of femoral head of were mixed with bioink and 3D bioprinted into square-shaped scaffolds consisting of 4 layers (total height $1.3 \mathrm{~mm}$ ) and $7-8 \mathrm{~mm}$ of diameter after 1,7 , and 21 days of cultivation. Additionally, the MC/alginate-based bioink laden with hMSCs was combined with $\mathrm{CPC}$

Encapsulated cells survived and redifferentiated within $\mathrm{MC}$ / alginate in the absence and presence of a mineral CPC phase. Collagen type II, sGAGs were produced in monophasic and biphasic constructs. The mineralized zone as located in the calcified cartilage region was found to support chondrogenic ECM production by altering the ionic concentrations of calcium and phosphorus the bioink maintained a roundish

Cell viability, DNA

Hodder et al. (2019) content, proteoglycans, nuclei, H\&E staining

Cell viability, luciferase assay, the levels of BMP2 and TGF- 33 , micro-computed tomography

Gonzalez-Fernandez et al. (2019)

Cell viability, GAGs

Roushangar Zineh et al. (2018)

Viability, cytoskeleton Ahlfeld et al. (2018) imaging

Viability, proliferation,

Kilian et al. (2020) cytoskeleton aggrecan, collagen II staining, sGAGs, collagen ॥ content, gene expression (COL1A1, COL2A1, COL10A1, ACAN, SOX9, COMP)

Electrospinning 
TABLE 2 | (Continued) Cellulose derivatives applied to cartilage tissue engineering

\begin{tabular}{|c|c|c|c|c|c|}
\hline $\begin{array}{l}\text { Cellulose } \\
\text { derivative } \\
\text { type }\end{array}$ & System & $\begin{array}{l}\text { Source of } \\
\text { chondrocytes or } \\
\text { stem cells } \\
\text { and experimental } \\
\text { design }\end{array}$ & Outcome & $\begin{array}{l}\text { Analyses related } \\
\text { to differentiation } \\
\text { and proliferation }\end{array}$ & Reference \\
\hline $\begin{array}{l}\text { NaCS/ } \\
\text { gelatine } \\
\text { scaffolds } \\
\text { disks }\end{array}$ & $\begin{array}{l}\text { NaCS incorporated into a fibrous } \\
\text { gelatin construct }\end{array}$ & $\begin{array}{l}\text { hBM-MSCs were grown } \\
\text { in pellet cultures or } \\
\text { seeded on NaCS/gelatine } \\
\text { scaffolds up to } 56 \text { days }\end{array}$ & $\begin{array}{l}\text { Pellet cultures supplemented } \\
\text { with NaCS expressed higher } \\
\text { aggrecan and collagen type II } \\
\text { gene expression than cultures } \\
\text { without NaCS and had a } \\
\text { chondrocyte-like morphology } \\
\text { with intensive proteoglycans } \\
\text { MSCs on NaCS/gelatine } \\
\text { scaffolds exhibited high } \\
\text { extracellular ECM-associated } \\
\text { gene expression }\end{array}$ & $\begin{array}{l}\text { Cell number, gene } \\
\text { expression (COL1A1, } \\
\text { COL2A1, COL1OA1, } \\
\text { ACAN, CHAD), } \\
\text { collagen II, } \\
\text { proteoglycans }\end{array}$ & \\
\hline $\begin{array}{l}\text { pSC/gelatine } \\
\text { scaffolds } \\
\text { disks }\end{array}$ & $\begin{array}{l}\text { pSC incorporated into a fibrous } \\
\text { gelatin construct }\end{array}$ & $\begin{array}{l}\text { hBM-MSCs were cultured } \\
\text { on pSC/gelatine scaffolds } \\
\text { up to } 56 \text { days }\end{array}$ & $\begin{array}{l}\text { In vitro } \\
\text { Expression of chondrogenic } \\
\text { markers was enhanced upon } \\
\text { increasing pSC concentration in } \\
\text { the scaffolds (up to } 5 \% \text { ) }\end{array}$ & $\begin{array}{l}\text { Cell proliferation, } \\
\text { cytoskeleton imaging, } \\
\text { gene expression } \\
(C O L 1 A 1, C O L 2 A 1, \\
C O L 10 A 1, A C A N, \\
\text { SOX9, CHAD), } \\
\text { collagen II }\end{array}$ & $\begin{array}{l}\text { Portocarrero Huang } \\
\text { et al. (2017) }\end{array}$ \\
\hline $\begin{array}{l}\text { psC/gelatine } \\
\text { scaffolds } \\
\text { disks }\end{array}$ & & $\begin{array}{l}\text { hBM-MSCs were cultured } \\
\text { on pSC/gelatine scaffolds } \\
\text { up to } 56 \text { days }\end{array}$ & $\begin{array}{l}\text { In vitro } \\
\text { MSCs undergoing } \\
\text { chondrogenesis had higher } \\
\text { expression of chondrogenic gene } \\
\text { expression and a more } \\
\text { homogenous cartilage-like matrix } \\
\text { with the highest ratio of collagens } \\
\text { type II to I on gelatin scaffolds } \\
\text { containing pSC in comparison to } \\
\text { native GAGs }\end{array}$ & $\begin{array}{l}\text { Cell proliferation, } \\
\text { sGAGs, collagen I, II, } \\
\text { aggrecan, gene } \\
\text { expression (MMP2, } \\
\text { COL1A1, COL2A1, } \\
\text { COL1OA1, ACAN, } \\
\text { CHAD, SOX9, VEGF) }\end{array}$ & $\begin{array}{l}\text { Menezes and Arinzeh, } \\
\text { (2020) }\end{array}$ \\
\hline $\begin{array}{l}\text { CAP } \\
\text { scaffolds }\end{array}$ & $\begin{array}{l}\text { Cellulose acetate phthalate (CAP) } \\
\text { dissolved using various combinations } \\
\text { of solvents }\end{array}$ & $\begin{array}{l}\text { Chick embryo } \\
\text { chondrocytes were } \\
\text { seeded on gelatin-coated } \\
\text { CAP scaffolds and } \\
\text { cultured up to } 12 \text { days }\end{array}$ & $\begin{array}{l}\text { In vitro } \\
\text { Attachment of the chondrocytes } \\
\text { on CAP scaffolds prepared using } \\
\text { dimethylformamide/ } \\
\text { tetrahydrofuran/acetone was } \\
\text { confirmed }\end{array}$ & H\&E staining & Shrestha et al. (2016) \\
\hline \multicolumn{6}{|l|}{ Membranes } \\
\hline $\begin{array}{l}\text { Cellulose } \\
\text { acetate } \\
\text { membrane } \\
\text { filter }\end{array}$ & & $\begin{array}{l}\text { Chondrocytes isolated } \\
\text { from human articular } \\
\text { cartilage of knee condyles } \\
\text { we transferred to } \\
\text { membranes and cultured } \\
\text { for up to } 21 \text { days }\end{array}$ & $\begin{array}{l}\text { In vitro } \\
\text { Membrane-based and pellet } \\
\text { cultures showed the ability to } \\
\text { promote redifferentiation of } \\
\text { chondrocytes expanded in } \\
\text { monolayer culture but } \\
\text { membrane-based cultures have } \\
\text { a short expression of COL } 2 A\end{array}$ & $\begin{array}{l}\text { H\&E staining, } \\
\text { proteoglycans, } \\
\text { collagen II, gene } \\
\text { expression (COL2A1) }\end{array}$ & $\begin{array}{l}\text { Mayer-Wagner et al. } \\
\text { (2011) }\end{array}$ \\
\hline $\begin{array}{l}\text { PVA/CMC } \\
\text { scaffolds }\end{array}$ & $\begin{array}{l}\text { Polyvinyl alcohol (PVA) was mixed } \\
\text { with CMC at different mass ratios. } \\
\text { Porous scaffolds were created by the } \\
\text { freeze-drying technique }\end{array}$ & $\begin{array}{l}\text { Human articular } \\
\text { chondrocytes were } \\
\text { seeded on scaffolds and } \\
\text { cultured for } 7 \text { days }\end{array}$ & $\begin{array}{l}\text { In vitro } \\
\text { The incorporation of CMC } \\
\text { modulated the pore architecture } \\
\text { and increases the swelling ratio of } \\
\text { scaffolds to promote cell } \\
\text { adhesion without cytotoxicity }\end{array}$ & Cell viability & Namkaew et al. (2021) \\
\hline
\end{tabular}

defects. Interestingly, in the canine osteochondral defect model, defects filled with Si-HPMC with or without adipose stromal cells, revealed a significant osteochondral regeneration (Boyer et al., 2020).

HEC (hydroxyethylcellulose) can serve as a cross-linking to form HEC/CS/GP hydrogels since chitosan can undergo sol-gel transition at $37^{\circ} \mathrm{C}$ when combined with GP and HEC. Apart from imitating the GAG structure, HEC/CS/GP hydrogels promote MSC survival and proliferation and chondrogenic differentiation of encapsulated chondrocytes and MSCs. As a result, this form of hydrogel may be used to patch cartilage defects during arthroscopic surgeries (Naderi-Meshkin et al., 2014).

Chemically sulfated cellulose may also serve as a scaffold for cartilage tissue engineering. Sulfation of cellulose improves 


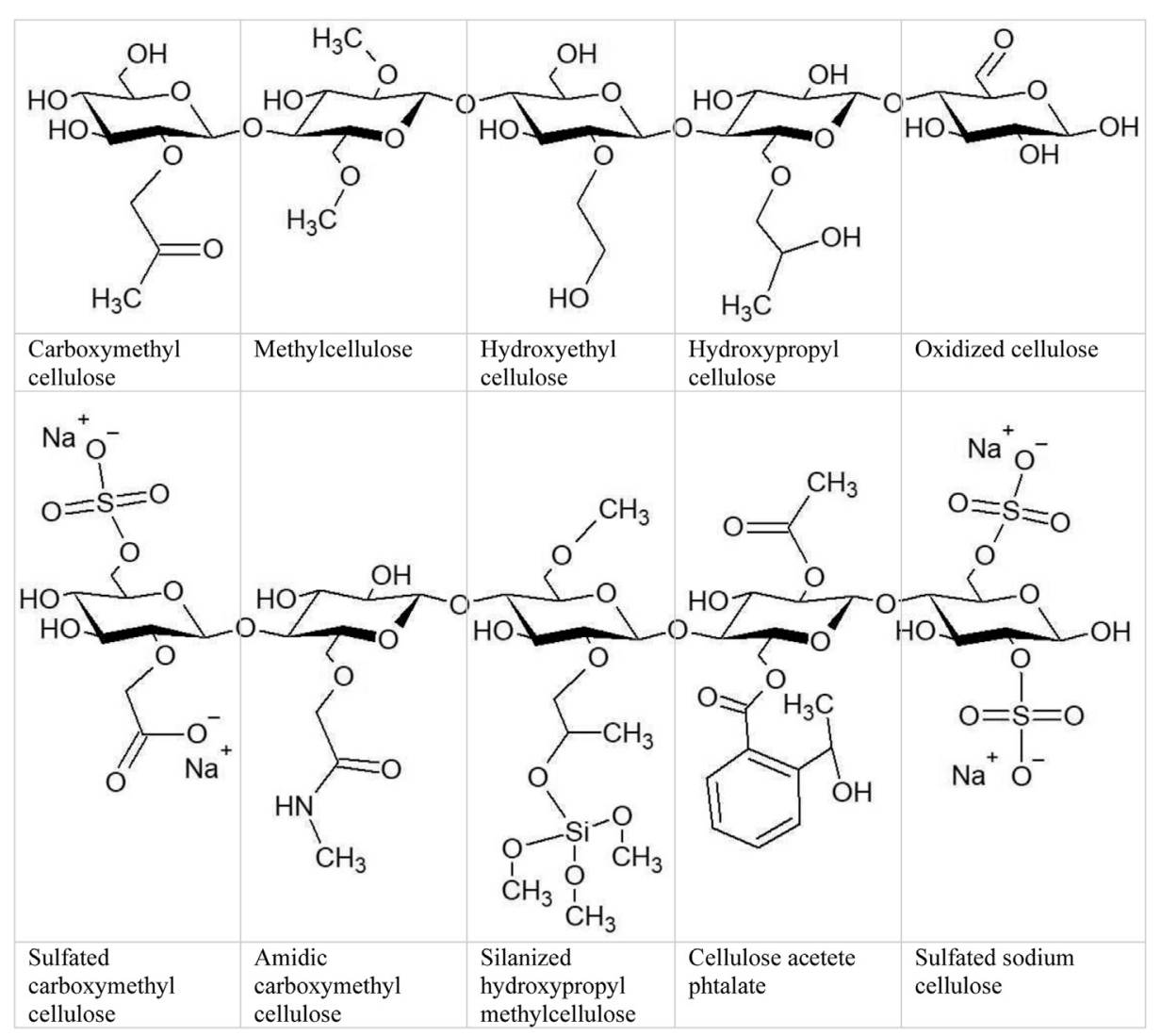

FIGURE 5 | Cellulose and its derivatives. Hydroxyl groups connected with carbon 2, 3 and/or 6 allows to formation esters or ethers bonds in variable ratio.

solubility with encapsulated MSCs disrupting intermolecular hydrogen bonds, potentially extending its applicability to a broader range of tissue engineering applications. Huang et al. investigated a completely sulfated version of sodium cellulose $(\mathrm{NaCS})$, which resulted in considerable collagen II and aggrecan upregulation by hBM-MSCs. Electrospinning was also used to create scaffolds containing $\mathrm{NaCS}$ and gelatin. The lowest concentration of $\mathrm{NaCS}(0.1 \%)$ resulted in the higher synthesis of collagen type II. Increased $\mathrm{NaCS}$ concentrations may hinder chondrogenesis because of irreversible growth factor-biomaterial binding (Huang et al., 2018). The same authors also used partially sulfated cellulose (pSC) in gelatin hydrogels. They found that increasing the pSC concentration in the scaffolds upregulated the expression of chondrogenic markers, indicating that pSC could be used as a scaffolding material for cartilage tissue engineering (Portocarrero Huang et al., 2017; Menezes and Arinzeh, 2020).

To overcome the limitations of native cellulose, chemical modifications are necessary. The fabrication of scaffolds using cellulose derivatives, i.e., MC, CMC, HPMC, HPC, or CA has been demonstrated with the aim of cartilage repair. The biomechanical and physicochemical features of cellulose derivatives depend on the nature of introduced chemical group and degree of substitution. Manipulating the concentrations of the solvent-soluble derivatives of cellulose can alter the stiffness of the formed hydrogels (Chinta et al., 2021). An overview of cellulose derivatives applied to cartilage tissue engineering is listed in Table 2.

\section{BNC-BASED SCAFFOLDS FOR CARTILAGE TISSUE ENGINEERING}

BNC-based hydrogels (Figure 6) are particularly interesting materials for cartilage tissue engineering because of their high purity (lack of hemicelluloses or lignins). In addition, BNC is biocompatible, has strong mechanical properties, a high water binding capacity, and a large surface area with many hydroxyl groups. Besides, 3D nanofibrous network of BNC resembles ECM.

But the lack of biodegradability of BNC, like with NFC or $\mathrm{CNC}$, is a serious disadvantage. However, methods to overcome this constraint have been developed, such as using a metabolically engineered $\mathrm{K}$. xylinus strain to produce lysozyme-modified degradable BNC (Yadav et al., 2010) or electron beam irradiation before implantation (An et al., 2017). Biodegradative resorption was also observed in the case of BNC-hydroxyapatite (BNC/HA) and BNC/GAG nanocomposite bilayered scaffolds that mimic bone and cartilage, respectively (Kumbhar et al., 2017). 
TABLE 3 | BNC applied to cartilage tissue engineering.

\begin{tabular}{|c|c|c|c|c|c|}
\hline BNC type & System & $\begin{array}{c}\text { Source of } \\
\text { chondrocytes or } \\
\text { stem cells } \\
\text { and experimental } \\
\text { design }\end{array}$ & Outcome & $\begin{array}{l}\text { Analyses related } \\
\text { to differentiation } \\
\text { and proliferation }\end{array}$ & Reference \\
\hline
\end{tabular}

Pure BNC hydrogels

$\mathrm{BNC}$

$\mathrm{BNC}$

BNC

BNC (Xellulin ${ }^{\circledR}$ )

Modified BNC

Sulfated,

phosphorylated and unmodified BNC membranes
DHYL/DBNC/CS microcarriers
Chemical sulfation with $\mathrm{NH}_{2} \mathrm{SO}_{3} \mathrm{H}$ Primary bovine chondrocytes and phosphorylation with $\mathrm{H}_{3} \mathrm{PO}_{4}$ and human articular cartilage of the BNC was performed to mimic GAGs of native cartilage chondrocytes were seeded on BNC membranes of 15
Equine BM-MSCs were seeded on BC scaffold discs and cultured up to 14 days

The central defects of the bovine cartilage discs were filled with the BNC and, after embedding the constructs into the agarose, a culture medium was added. The constructs were kept for up to 8 weeks

Rabbit BM-MSC were seeded on BNC discs and cultured up to 14 days

Human articular OA and nonOA chondrocytes were cultured in high density (HD) culture on a BNC for 7 days and $8 \mathrm{~mm}$ diameter, respectively and cultured for 8 days

Nanofibrous microcarriers (NFMCs) were prepared by crosslinking C2, 3-dialdehyde bacterial cellulose (DBNC), prepared by oxidation of BNC by $\mathrm{NalO}_{4}$ solutions, with DL-allohydroxylysine (DHYL) and complexing CS with DHYL
BM-MSCs with NF-MCs were cultured under
In vitro

The BNC scaffolds were

shown to be cytocompatible, supporting cellular adhesion

and proliferation, and allowed for chondrogenic differentiation of MSCs Ex vivo

Cartilage discs displayed a

preserved structural and functional integrity of the chondrocytes and surrounding matrix.

Chondrocytes on the BNC surface showed signs of redifferentiation

In vitro

BNC allowed the adhesion, expansion, and biointegration of BM-MSCs

In vitro

Chondrocytes kept the

potential to express COL2A1

in all systems (pellet, HD

hydrogel, and HD

polystyrene). However, pellets did not develop degeneration and dedifferentiation markers

In vitro

The chemical modifications did not enhance chondrocyte growth, while the material's porosity supported viability and more extended morphology. Unmodified BNC supported viability of chondrocytes and did not induce the cells to differentiate into fibroblasts In vitro

BM-MSCs cultured in NF-

MCs showed improved

proliferation compared with
Cellular adhesion, viability

Favi et al. and proliferation, SEM,

(2013)

GAGs

Aggrecan, collagen I, II, newly synthesized and cleaved collagen II, SEM, gene expression (ACAN, COL1A1, COL2A1), sGAGs

Pretzel et al. (2013)

Cell viability, SEM

Silva et al. (2018)

Proteoglycans, gene Grigull et al. expression (ACAN, SOX9,
Cell viability, adhesion morphology, gene expression (COL1A1, COL2A1)

Cell viability, GFP imaging, H\&E, proteoglycans, collagen II, micro- computed tomography, gait analysis
Svensson et al. (2005) those cultured in CS microcarriers. Under microgravity conditions, functional cartilage was generated
In vivo
The functional microtissue was used to repair a critical- size osteochondral defect successfully and was shown to be advantageous for tissue healing in a short time post- operation
In vivo 7 days or GFP-labe cultured in a microgravity NF-MCs alone (selected with GFP-labeled BM-MSCs injected into rat femoral trochlear cartilage defect up to12 weeks MSCs with NF-MCs a pore size of $35 \mu \mathrm{m}$ ) or with

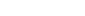

Macroscopic examination

(Continued on following page) 
TABLE 3 | (Continued) BNC applied to cartilage tissue engineering.

\begin{tabular}{|c|c|c|c|c|}
\hline BNC type & System & $\begin{array}{c}\text { Source of } \\
\text { chondrocytes or } \\
\text { stem cells } \\
\text { and experimental } \\
\text { design }\end{array}$ & Outcome & $\begin{array}{l}\text { Analyses related } \\
\text { to differentiation } \\
\text { and proliferation }\end{array}$ \\
\hline
\end{tabular}

Modified BNC membrane

\section{Modified BNC} membrane

Densified BNC

Air dried and freeze dried BNC

BNC with relaxed fibers structure

Porous BNC

Porous BNC
The artificial human auricle made of a BNC membrane, at least $25 \mathrm{~mm}$ thick, subjected to physical modification, including mold compression and placed in a bath with a high concentration of sodium hydroxide

\section{Modified BNC produced from} $\mathrm{N}$-acetylglucosamine-fed cultures from metabolically engineered $K$. xylinus characterized by low crystallinity and lysozyme susceptibility
BNC's subcutaneous artificial human auricle in the back of rats for $14,30,90$, or 720 days

Human BM-MSCs were seeded on scaffolds $(6 \mathrm{~mm}$ diameter discs) and cultured up to 4 weeks implantation resembles

Resection after 14, 30, 90 and 720 days showed progression of the healing process and integration of the artificial skeleton into the animal body. There were no signs of change in the shape or structure of the skeleton In vitro

Porous scaffolds (pore sizes larger than the cells) supported hBM-MSCs attachment, proliferation and cartilage-specific matrix biosynthesis. The spatial cell arrangement and collagen type II and ACAN distribution resembled those in native articular cartilage tissue In vivo

The biocompatibility tests demonstrated that densified BNC hydrogels are non-

cytotoxic and cause a minimal foreign body response

In vitro

BNC was dried by air drying under Rat MSCs were seeded on

MotAB + BNC with relaxed ambient condition and freeze drying to produce BNC layers having different compressive moduli

BNC produced by genetically modified strain $(K$. hansenii ATCC $23769 \operatorname{mot} A B+$ strain)
ATDC5 cells were seeded on $\mathrm{BNC}$ discs and cultured up to 21 days
MSCs attached and spread

on the surface of the BNC.

The softer freeze dried BNC promoted the differentiation of MSCs into chondrocytes. The differentiation was found to be difficult without using the differentiation agents In vitro fiber structure supported ATDC5 cells growth to a higher extent than the wildtype BNC. ATDC5 cells seeded on motAB + BNC secreted the highest levels of GAGs

In vitro

Scaffolds obtained by cultivating K. xylinus in the presence of agarose microparticles deposited on the surface of a growing BNC pellicle

Human primary chondrocytes were seeded on scaffolds ( $40 \mathrm{~mm}$ in diameter) and cultured up to 14 days

The introduction of pores with a size of $300-500 \mu \mathrm{m}$ enabled chondrocytes to penetrate scaffolds, migrate and proliferate.

Chondrocytes seeded on scaffolds displayed a 3D distribution extending throughout the porous BNC network

In vitro

Porous BNC was produced by Human primary paraffin beads embedded during the fermentation process

chondrocytes derived from rseptorhino- and otoplasties were seeded on scaffold and cultured up to 14 days
Chondrocytes adhered to BNC, re-differentiated, produced cartilaginous matrix proteins and were
Miśkiewicz

et al. (2019)

Cell viability, proliferation,

Yadav et al. SEM, sGAG content, gene expression (ACAN, SOX9, COL2A1), collagen II

(2015) $\begin{array}{ll}\text { H\&E } & \text { Martínez } \\ & \text { Ávila et al. } \\ & (2014)\end{array}$

Cell viability, morphology, Taokaew GAGs
Cell viability, morphology, Jacek et al. GAGs (2018)

Cell proliferation viability, $\quad$ Yin et al. cytoskeleton imaging, SEM (2015)

Adhesion, agreccan,

Feldmann collagen II, gene expression et al. (2013) (COL1A1, COL2A1, VCAN) 
TABLE 3 | (Continued) BNC applied to cartilage tissue engineering.

\begin{tabular}{|c|c|c|c|c|}
\hline BNC type & System & $\begin{array}{c}\text { Source of } \\
\text { chondrocytes or } \\
\text { stem cells } \\
\text { and experimental } \\
\text { design }\end{array}$ & Outcome & $\begin{array}{l}\text { Analyses related } \\
\text { to differentiation } \\
\text { and proliferation }\end{array}$ \\
\hline
\end{tabular}

Porous BNC scaffold Porous BNC scaffolds were prepared by fermentation of $K$. xylinus in the presence of slightly fused wax particles with a diameter of 150-300 $\mu \mathrm{m}$, which were then removed by extrusion

Perforated BNC

Composites

BNC/alginate bioink $\quad B N C$ was disentangled into single cellulose nanofibrils by hydrolysis or aqueous counter collision (ACC) method that dissociates weaker intermolecular interaction, without chemical modification

$\mathrm{BNC} / \kappa-$ Car composites were prepared using in situ method with supplementation of the medium with $\kappa$-carragen ( $\kappa$-Car)

GelMA/BNC

$\mathrm{BNC} / \mathrm{HA}$ and BNC/GAG

GelMA/BNC composite hydrogels were prepared by immersing BNC particles, obtained by homogenization of BNC membranes, in GelMA solution followed by photocrosslinking

Nanocomposites of BNC/HA were synthesized using simulated
Neonatal articular chondrocytes from a cell line from the distal end of metacarpal phalangeal bone cells were seeded onto rectangular-shaped scaffolds $\left(0.25 \mathrm{~cm}^{2}\right)$ and cultured up to 14 days. Chondrocytes from human cartilage were seeded on scaffolds and cultured up to 28 days

Bovine and human articular chondrocytes were seeded on BNC samples up to 21 days

hNCs mixed with ACC bioink and 3D bioprinted into the lattice-shaped constructs (5 $\times 5 \times 1 \mathrm{~mm}$ with $1.2 \mathrm{~mm}$ spacing) were implanted into subcutaneous pockets on the backs of the nude mice up to 60 days

ATDC5 cells were seeded on BNC discs and cultured up to 21 days body fluid. BNC/GAG were prepared by incubation of BNC scaffolds with chondroitin sulfate sodium salt suspensions and LAP. After UV light exposure cells were cultured up to 14 days

Human articular chondrocytes or human ATSCs were seeded on scaffolds up to 28 days Scaffolds were inserted into a rat subcutaneous pocket located within the pores. Variations in pore sizes of 150-300 $\mu \mathrm{m}$ and 300-500 $\mu \mathrm{m}$ did not influence ECM synthesis In vitro

Cells tended to cluster within the pores, with cells only entering the pores at the surface layer. Cells produced ECM components in scaffolds when being arranged closely to each other

In vitro

Unidirectionally perforated and in particular 3Dperforated BNC allowed ingrowth into and movement of chondrocytes throughout the BNC matrix. Cells displayed clear signs of redifferentiation

\section{In vivo}

Cell-laden structures were rapidly integrated, maintained structural integrity, and showed chondrocyte proliferation. Production of collagen II and GAGs was observed. FISH analysis confirmed that the GAGpositive cells in the 3Dbioprinted constructs were mainly of human origin

In vitro

$\mathrm{BNC} / \kappa-$ Car composites supported the differentiation of ATDC5 cells to more chondrogenic phenotype and did not cause the chondrocyte hypertrophy In vitro

Fluorescent stainings of SOX9, type II collagen and aggrecan were positive in most of the chondrocytes created in the region
In vitro

Higher proliferation and synthesis of sGAGs by chondrocytes and ATSCs was observed of on BNC/ GAG scaffolds In vivo
SEM, confocal microscopy, Andersson GAGs, DNA content et al. (2010)

Viability, H\&E, GAGs, gene expression (ACAN, COMP

Ahrem et al. COL1A1, COL2A1, COL9A1)

GAGs, collagen ॥, FISH

Cell viability, gene expression Cielecka (COL1A1, COL2A1, RUNX2, et al. (2018) SOX9)

Cell viability, collagen II, Gu et al. aggrecan, SOX9 (2021)

Cell viability, cytoskeleton

Kumbhar imaging, sGAGs, et al. (2017) proteoglycans, microcomputed tomography

(Continued on following page) 
TABLE 3 | (Continued) BNC applied to cartilage tissue engineering.

\begin{tabular}{|c|c|c|c|c|c|}
\hline BNC type & System & $\begin{array}{c}\text { Source of } \\
\text { chondrocytes or } \\
\text { stem cells } \\
\text { and experimental } \\
\text { design }\end{array}$ & Outcome & $\begin{array}{l}\text { Analyses related } \\
\text { to differentiation } \\
\text { and proliferation }\end{array}$ & Reference \\
\hline & & $\begin{array}{l}\text { corresponding to the lower } \\
\text { thoracic vertebrae up to } \\
45 \text { days } \\
\text { Bilayer scaffold (BNC/HA and } \\
\text { BNC/GAG placed one over } \\
\text { the other) were implanted } \\
\text { into rat osteochondral defect } \\
\text { created in the patellar groove } \\
\text { of the knee joints for } 90 \text { days }\end{array}$ & $\begin{array}{l}\text { The scaffolds allowed tissue } \\
\text { ingrowth with no } \\
\text { inflammation or } \\
\text { immunological reactions. } \\
\text { Implantation of acellular } \\
\text { bilayered scaffolds in } \\
\text { osteochondral defect } \\
\text { simultaneously accelerated } \\
\text { the regeneration of articular } \\
\text { cartilage and subchondral } \\
\text { bone. Scaffolds displayed } \\
\text { excellent biodegradative } \\
\text { resorption properties }\end{array}$ & & \\
\hline Bilayer BNC scaffolds & $\begin{array}{l}\text { Bilayer scaffold (densified BNC } \\
\text { layer and BNC/alginate porous } \\
\text { layer) was produced with ionic } \\
\text { liquid used to attach the layers } \\
\text { BNC disks with cellulose content } \\
\text { of } 17 \% \text { were produced by } \\
\text { compression, whereas BNC/ } \\
\text { alginate composite scaffolds were } \\
\text { fabricated by a freeze-drying }\end{array}$ & $\begin{array}{l}\text { hNCs were seeded on BNC } \\
\text { scaffolds and cultured for up } \\
\text { to } 6 \text { weeks } \\
\text { hNCs and bone marrow } \\
\text { mononuclear cells } \\
\text { encapsulated in alginate } \\
\text { were seeded in bilayer BNC } \\
\text { scaffolds and implanted } \\
\text { subcutaneously on the dorsal } \\
\text { side of nude mice for } \\
8 \text { weeks }\end{array}$ & $\begin{array}{l}\text { In vitro } \\
\text { Bilayer BNC scaffolds } \\
\text { supported the } \\
\text { redifferentiation of NCs to a } \\
\text { more chondrogenic } \\
\text { phenotype, which led to } \\
\text { neocartilage formation. The } \\
\text { high porosity layer ( } 75 \% \\
\text { porosity with a mean pore } \\
\text { size of } 50 \pm 25 \text { um) } \\
\text { supported the ingrowth and } \\
\text { homogeneous distribution } \\
\text { of NCs } \\
\text { In vivo } \\
\text { Deposition of cartilage matrix } \\
\text { components were observed } \\
\text { in constructs. The results } \\
\text { showed the formation of } \\
\text { neocartilage in the porous } \\
\text { layer }\end{array}$ & $\begin{array}{l}\text { GAGs, aggrecan, collagen I, } \\
\text { II, gene expression (ACAN, } \\
\text { VCAN, COL2A1, COL1A1), } \\
\text { proteoglycans }\end{array}$ & $\begin{array}{l}\text { Martínez } \\
\text { Ávila et al. } \\
\text { (2015) }\end{array}$ \\
\hline $\begin{array}{l}\text { BNC double-network } \\
\text { hydrogel }\end{array}$ & $\begin{array}{l}\text { The bilayer structure with two } \\
\text { different hydrogel layers (PGA } \\
\text { alginate) with incorporated BNC } \\
\text { was synthesized via a three-step } \\
\text { cross-linking procedure. } \\
\text { Additionally, hydroxyapatite } \\
\text { particles with two different sizes } \\
\text { were introduced into the bilayer } \\
\text { hydrogels, for promoting cartilage } \\
\text { matrix deposition and for } \\
\text { enhancing compression modulus } \\
\text { and osteogenesis }\end{array}$ & $\begin{array}{l}\text { Hydrogels were implanted } \\
\text { into a cylindrical } \\
\text { osteochondral defect in the } \\
\text { rabbit medial femoral condyle } \\
\text { for } 12 \text { weeks }\end{array}$ & $\begin{array}{l}\text { In vivo } \\
\text { The newborn hyaline cartilage } \\
\text { with smooth surface and the } \\
\text { subchondral bone } \\
\text { reconstruction was observed } \\
\text { at } 12 \text { weeks postoperation, } \\
\text { which is much faster than the } \\
\text { reported similar bilayer } \\
\text { hydrogel scaffold without } \\
\text { hydroxyapatite }\end{array}$ & $\begin{array}{l}\text { H\&E, micro- computed } \\
\text { tomography }\end{array}$ & $\begin{array}{l}\text { Zhu et al. } \\
\text { (2018) }\end{array}$ \\
\hline
\end{tabular}

Another limitation of employing BNC for cartilage tissue engineering applications is the pore size of BNC (diameter of $\sim 0.02-10 \mu \mathrm{m}$ depending on the bacterial strain and the culture conditions) that is smaller than the diameters of mammalian cells. This feature prevents cells from migration across the scaffold. The upper surface of BNC (in contact with air) has a dense architecture with much smaller pores (below $2 \mu \mathrm{m}$ ), whereas the lower surface (in contact with the culture liquid) has pores with a much bigger diameter (Ahrem et al., 2014). Cell attachment, migration, and ingrowth are all influenced by the scaffold's pore size. Large pores in the scaffold allow efficient delivery of nutrients, gas diffusion, and metabolic waste disposal. Still, they can also contribute to poor cell attachment and intracellular signaling, whereas tiny pores can have the opposite effect. Chondrocytes were shown to prefer scaffolds with pore sizes ranging from 250 to $500 \mu \mathrm{m}$ for improved proliferation and ECM synthesis. The growth rate, the amount of GAG secretion, and the expressions of the 


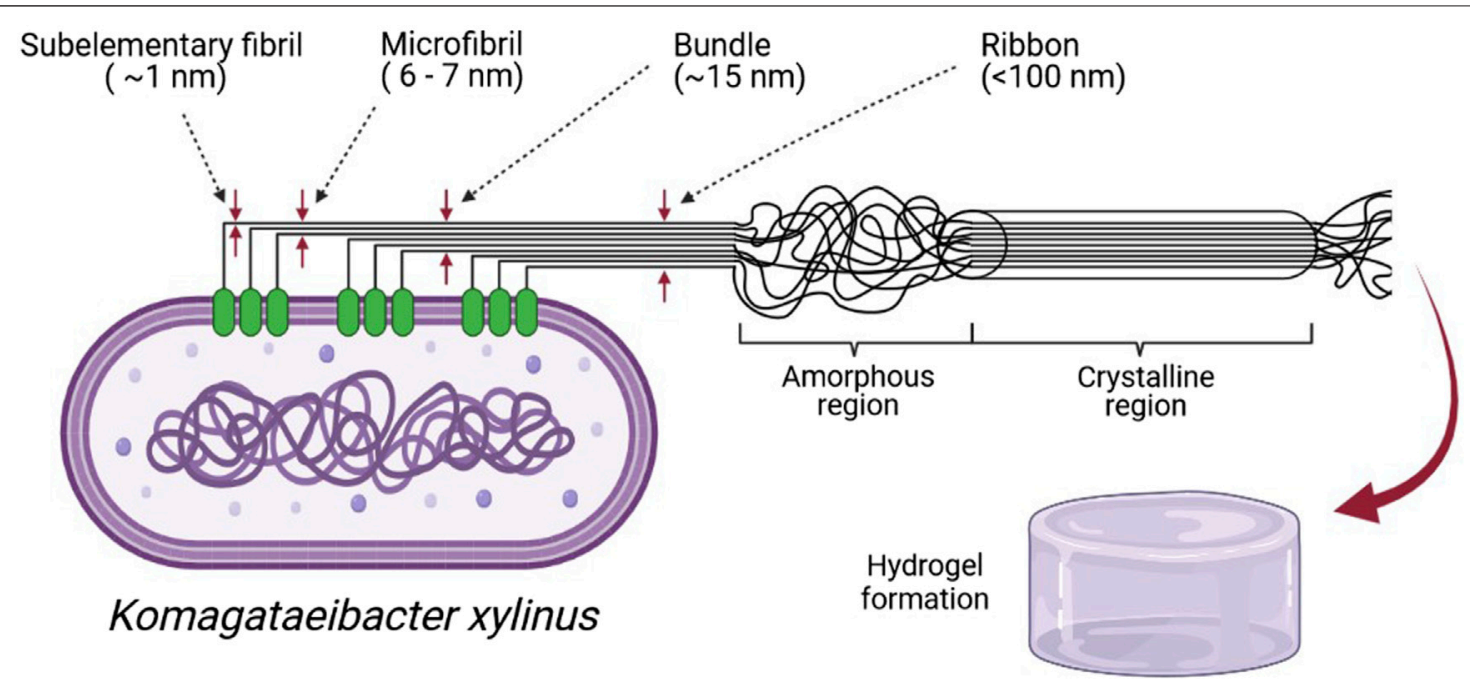

FIGURE 6|Bacterial cellulose is produced by cellulose synthases found in groups in the cell wall and (Lee et al., 2014). Cellulose is pulled outside the cell and subelementary fibril is formed. During cell movement, extracted cellulose connect and create microfibrils, bundles, and ribbons. BNC, besides high purity, is characterized by a high crystalline region (80-90\%) (Lee et al., 2014), a part with high stacked polysaccharide chains. Komagateibacter during stationary culture produce BNC in a form of hydrogel (created in BioRender.com).

differentiation gene markers increased as the pore size became larger. On the other hand, the cells growing on scaffolds with the smaller pores were frequently found to be dedifferentiated (Lien et al., 2009).

Several methods have attempted to create porous BNC scaffolds, e.g., cultivating K. xylinus with porogen materials (Bäckdahl et al., 2008). When porogen/particle-leaching approaches are employed, the porogen particles are removed from the system by a leaching process, leaving a highly porous polymer scaffold. Paraffin wax particles of $150-300 \mu \mathrm{m}$ in diameter were used as a porogen to form a porous $\mathrm{BNC}$ material evaluated as a scaffold for cartilage regeneration. Human chondrocytes entered the pores to some extent and synthetized ECM components. However, removing wax from $\mathrm{BNC}$ and controlling the size of pores are issues to deal with. Besides, even though human chondrocytes tolerated the sponge-like material created with this method, penetration of these cells into the scaffold was limited to the outermost layers (Andersson et al., 2010). BNC porosity generated by paraffin beads was also demonstrated to augment a chondrogenic phenotype of nasal and auricular chondrocytes (Feldmann et al., 2013). Another example of porous BNC scaffolds formation includes cultivating $K$. xylinus in the presence of agarose microparticles. Using a microfluidic method, monodispersed agarose microparticles with a diameter of $300-500 \mu \mathrm{m}$ were deposited over synthetized BNC pellicles and integrated into the polymer when $K$. xylinus cells migrated upward through the growing pellicle. As a result, human chondrocytes divided, infiltrated the $3 \mathrm{D}$ porous network, were uniformly distributed, and had better viability compared to unmodified BNC (Yin et al., 2015). Using bilayer BNC composites (micro-porous layer created by freeze drying with alginate beads) implanted subcutaneously into mice confirmed that such composites have good mechanical stability, preserve structural integrity, and enable cell ingrowth. For in vivo studies bilayer BNC scaffolds were seeded with a low number of freshly isolated human chondrocytes combined with freshly isolated mononuclear cells. After 8 weeks chondrocytes showed the deposition of proteoglycans and type II collagen (Martínez Ávila et al., 2015). Other BNC porous composites containing GAGs placed on the surface of the cellulose membrane (BNC/GAG) were found to promote chondrogenesis and facilitate infiltration of host tissue, resulting in a well-spread blood vascular network at the implantation site (Kumbhar et al., 2017).

Laser perforation by post-processing step is another technology that has shown promise to modify BNC surface morphology. Generally, laser treatments create parallel-channel arrays of pores (Jing et al., 2013). Ahrem et al. demonstrated the possibility of $3 \mathrm{D}$ laser perforation of $\mathrm{BNC}$ hydrogels with a pulsed $\mathrm{CO}_{2}$ laser system which generated round-shaped channels of specified arrangement. The 3D-perforated BNC had high biocompatibility, and the resultant channels allowed chondrocytes to migrate into the $\mathrm{BNC}$, produce matrix, and maintain their phenotypic stability (Ahrem et al., 2014).

Genetic modifications of BNC-producing strains are the next option. BNC with relaxed fiber structure was obtained by overexpression of motA and $\operatorname{mot} B$ genes in $K$. hansenii ATCC 23769. MotA and motB form a proton pump and are thought to be involved in cell motility. Their overexpression (motA+, $\operatorname{mot} \mathrm{B}+$, and $\operatorname{mot} \mathrm{AB}+$ ) resulted in bacterial cell elongation (or filament production) and increased colony-spreading abilities, making BNC more porous and relaxed. The K. hansenii mutantderived BNC appeared to be potential support for the growth of chondrogenic cells and encouraged their chondrogenic-like activity (Jacek et al., 2018). 
Because $\mathrm{BNC}$ and plant-derived $\mathrm{NC}$ have similar chemical compositions, BNC can be modified using the same chemical procedures, namely phosphorylation, carboxylation, or acetylation. Chemical sulfation and phosphorylation of BNC can add a charge and mimic GAGs of native cartilage. However, in this particular case, those modifications did not affect chondrocyte growth (Svensson et al., 2005). Other studies have shown that composite hydrogels with BNC can also be utilized to support differentiation and growth of chondrocytes and MSCs. BNC with a $17 \%$ increase in cellulose concentration was comparable to auricular cartilage in terms of mechanical strength and host tissue reaction. The implants were strongly attached to the surrounding soft tissue after 1 week of retention in the body, while blood and tissue fluid were absorbed into the implant material (Martínez Ávila et al., 2014).

Because of its unique physiochemical characteristics and outstanding biocompatibility, BNC has emerged as a viable biomaterial for cartilage tissue engineering applications. The simplicity with which it may be adjusted to suit any desired direction by chemical reactions, structural modifications, or the incorporation of active components into the BNC structure has made it an excellent biomaterial for preparing scaffolds. To improve issues connected with biodegradability and porosity, enzymatic chemical, and genetic engineering technologies could be used. An overview of BNC applied to cartilage tissue engineering is listed in Table 3.

\section{CONCLUSION}

Repairing cartilage tissue remains a serious clinical challenge. The global prevalence of cartilage problems has risen rapidly in recent years, and it is expected to quadruple by 2040 (Stampoultzis et al., 2021). With the rapid breakthroughs in tissue engineering, cartilage regeneration via transplantation of artificial constructs has become a viable approach. However, despite promising results in vitro, the lack of artificial constructs that mimic the native tissue's biomechanical and biochemical milieu has hampered its application in clinical practice.

Very challenging aspects of cartilage TE are related to selecting the cell source together with cellular differentiation and expansion. Chondrocytes appear to be the most promising starting material that promises the regeneration and healing of cartilage. Even though chondrocytes seem to be the primary choice, difficulties such as low proliferation rate and dedifferentiation are likely. Due to restricted sources and challenging collection processes, differentiated chondrocytes are difficult to obtain in appropriate amounts. As a result, other cell sources have been investigated, and the use of mesenchymal stem cells is an effective and safe technique to stimulate chondrogenesis. Therefore, an optimal scaffold would be one that can maintain a balance between chondrocyte proliferation and MSC differentiation within a 3D matrix (Grigolo et al., 2011).

Nanocellulose offers excellent potential in tissue engineering because of its biocompatibility, non-toxicity, water holding capacity, and superior mechanical properties. Exploitation of plant-derived biopolymers in $\mathrm{TE}$ is a new sector with untapped promise for developing more advanced functional materials from the world's most plentiful and sustainable resources, as well as responding to global trends toward customized medicine and therapy (Xu et al., 2018). Nanocellulose is now widely used as part of a new generation of nanomaterials for versatile global biomedical applications due to the promotion of cellular interactions and tissue development mimicking the extracellular matrix. Although currently NC application in cartilage tissue engineering is mainly at the laboratory stage, in the future, personalized implants can be manufactured using $3 \mathrm{D}$ printing technology. NFC, in particular, meets the application criteria for bioplotting, inkjet printing, and extrusion-based printing due to its inherent gelformability (Markstedt et al., 2015). Also, BNC is a unique functional material that has already demonstrated considerable promise for biological applications in its natural state (Pretzel et al., 2013) or as a component of bioinks (Apelgren et al., 2019). Furthermore, its ability to be modified and composited underlines its suitable position in cartilage tissue engineering (Svensson et al., 2005).

However, obstacles must be overcome before NC-based biomaterials will be used in therapeutic settings. The safety related to long-term stability of the regenerated cartilage is an important issue. NC degrades slowly in the human body due to the lack of enzymes that break $\beta-1,4$ glycosidic bonds. Also, a high degree of crystallinity may contribute to its nonbiodegradability. Therefore, many attempts have been made to improve the degradability of cellulose products in vivo (e.g., Yadav et al., 2010; An et al., 2017). On the other hand, nonbiodegradable NC could be employed as a long-lasting support material in applications such as cartilage meniscus implants.

Another essential difficulty restricting nanocellulose's use is its pore size. Scaffolds for cartilage regeneration should provide not only mechanical support but porous architecture. Pore size itself is also critical. It needs to be large enough to allow cell movement and complete ECM synthesis and small enough to allow cells to attach to a broad surface area (Zhang et al., 2014).

Despite the limits mentioned above, nanocellulose holds promise as a cartilage tissue engineering scaffold. In the long run, this biomaterial has the potential to improve life quality and comfort. However, more research is needed to investigate the long-term impacts of the NC-based scaffolds on the physiology of chondrocyte or stem cells.

\section{AUTHOR CONTRIBUTIONS}

EG-D: conceptualization, writing, and preparing the tables. MS: preparing the figures and writing. All authors contributed to the manuscript and approved the submitted version.

\section{ACKNOWLEDGMENTS}

This is a short text to acknowledge the contributions of specific colleagues, institutions, or agencies that aided the efforts of the authors. 


\section{REFERENCES}

Ahlfeld, T., Doberenz, F., Kilian, D., Vater, C., Korn, P., Lauer, G., et al. (2018). Bioprinting of Mineralized Constructs Utilizing Multichannel Plotting of a SelfSetting Calcium Phosphate Cement and a Cell-Laden Bioink. Biofabrication 10, 045002. doi:10.1088/1758-5090/aad36d

Ahmed, T. A. E., and Hincke, M. T. (2010). Strategies for Articular Cartilage Lesion Repair and Functional Restoration. Tissue Eng. B: Rev. 16, 305-329. doi:10.1089/ten.teb.2009.0590

Ahrem, H., Pretzel, D., Endres, M., Conrad, D., Courseau, J., Müller, H., et al. (2014). Laser-structured Bacterial Nanocellulose Hydrogels Support Ingrowth and Differentiation of Chondrocytes and Show Potential as Cartilage Implants. Acta Biomater. 10, 1341-1353. doi:10.1016/j.actbio.2013.12.004

Al-Sabah, A., Burnell, S. E. A., Simoes, I. N., Jessop, Z., Badiei, N., Blain, E., et al. (2019). Structural and Mechanical Characterization of Crosslinked and Sterilised Nanocellulose-Based Hydrogels for Cartilage Tissue Engineering. Carbohydr. Polym. 212, 242-251. doi:10.1016/j.carbpol.2019.02.057

Almouemen, N., Kelly, H. M., and O'Leary, C. (2019). Tissue Engineering: Understanding the Role of Biomaterials and Biophysical Forces on Cell Functionality through Computational and Structural Biotechnology Analytical Methods. Comput. Struct. Biotechnol. J. 17, 591-598. doi:10.1016/ j.csbj.2019.04.008

An, S.-J., Lee, S.-H., Huh, J.-B., Jeong, S., Park, J.-S., Gwon, H.-J., et al. (2017). Preparation and Characterization of Resorbable Bacterial Cellulose Membranes Treated by Electron Beam Irradiation for Guided Bone Regeneration. Int. J. Mol. Sci. 18, 2236. doi:10.3390/ijms 18112236

Andersson, J., Stenhamre, H., Bäckdahl, H., and Gatenholm, P. (2010). Behavior of Human Chondrocytes in Engineered Porous Bacterial Cellulose Scaffolds. J. Biomed. Mater. Res. 9999A, NA. doi:10.1002/jbm.a.32784

Apelgren, P., Amoroso, M., Lindahl, A., Brantsing, C., Rotter, N., Gatenholm, P., et al. (2017). Chondrocytes and Stem Cells in 3D-Bioprinted Structures Create Human Cartilage In Vivo. PLoS ONE 12, e0189428. doi:10.1371/ journal.pone. 0189428

Apelgren, P., Amoroso, M., Säljö, K., Lindahl, A., Brantsing, C., Stridh Orrhult, L., et al. (2018). Skin Grafting on 3D Bioprinted Cartilage Constructs In Vivo. Plast. Reconstr. Surg. - Glob. Open 6, e1930. doi:10.1097/gox.0000000000001930

Apelgren, P., Amoroso, M., Säljö, K., Lindahl, A., Brantsing, C., Stridh Orrhult, L., et al. (2021). Long-term In Vivo Integrity and Safety of 3D -bioprinted Cartilaginous Constructs. J. Biomed. Mater. Res. 109, 126-136. doi:10.1002/jbm.b.34687

Apelgren, P., Karabulut, E., Amoroso, M., Mantas, A., Martínez Ávila, H., Kölby, L., et al. (2019). In Vivo Human Cartilage Formation in Three-Dimensional Bioprinted Constructs with a Novel Bacterial Nanocellulose Bioink. ACS Biomater. Sci. Eng. 5, 2482-2490. doi:10.1021/acsbiomaterials.9b00157

Arora, A., Mahajan, A., and Katti, D. S. (2017). TGF- $\beta 1$ Presenting Enzymatically Cross-Linked Injectable Hydrogels for Improved Chondrogenesis. Colloids Surf. B: Biointerfaces 159, 838-848. doi:10.1016/j.colsurfb.2017.08.035

Aswathy, S. H., Narendrakumar, U., and Manjubala, I. (2020). Commercial Hydrogels for Biomedical Applications. Heliyon 6, e03719. doi:10.1016/ j.heliyon.2020.e03719

Augustyniak, E., Trzeciak, T., Richter, M., Kaczmarczyk, J., and Suchorska, W. (2015). The Role of Growth Factors in Stem Cell-Directed Chondrogenesis: a Real hope for Damaged Cartilage Regeneration. Int. Orthopaedics (Sicot) 39, 995-1003. doi:10.1007/s00264-014-2619-0

Bäckdahl, H., Esguerra, M., Delbro, D., Risberg, B., and Gatenholm, P. (2008). Engineering Microporosity in Bacterial Cellulose Scaffolds. J. Tissue Eng. Regen. Med. 2, 320-330. doi:10.1002/term.97

Balakrishnan, B., Joshi, N., and Banerjee, R. (2013). Borate Aided Schiff's Base Formation Yields In Situ Gelling Hydrogels for Cartilage Regeneration. J. Mater. Chem. B. 1, 5564-5577. doi:10.1039/c3tb21056a

Begum, R., Perriman, A. W., Su, B., Scarpa, F., and Kafienah, W. (2020). Chondroinduction of Mesenchymal Stem Cells on Cellulose-Silk Composite Nanofibrous Substrates: The Role of Substrate Elasticity. Front. Bioeng. Biotechnol. 8, 1-14. doi:10.3389/fbioe.2020.00197

Benthien, J. P., and Behrens, P. (2011). The Treatment of Chondral and Osteochondral Defects of the Knee with Autologous Matrix-Induced Chondrogenesis (AMIC): Method Description and Recent Developments.
Knee Surg. Sports Traumatol. Arthrosc. 19, 1316-1319. doi:10.1007/s00167010-1356-1

Boyer, C., Figueiredo, L., Pace, R., Lesoeur, J., Rouillon, T., Visage, C. L., et al. (2018). Laponite Nanoparticle-Associated Silated Hydroxypropylmethyl Cellulose as an Injectable Reinforced Interpenetrating Network Hydrogel for Cartilage Tissue Engineering. Acta Biomater. 65, 112-122. doi:10.1016/ j.actbio.2017.11.027

Boyer, C., Réthoré, G., Weiss, P., d'Arros, C., Lesoeur, J., Vinatier, C., et al. (2020). A Self-Setting Hydrogel of Silylated Chitosan and Cellulose for the Repair of Osteochondral Defects: From In Vitro Characterization to Preclinical Evaluation in Dogs. Front. Bioeng. Biotechnol. 8, 23. doi:10.3389/ fbioe.2020.00023

Brose, T. Z., Kubosch, E. J., Schmal, H., Stoddart, M. J., and Armiento, A. R. (2015). Crosstalk between Mesenchymal Stromal Cells and Chondrocytes: The Hidden Therapeutic Potential for Cartilage Regeneration. Stem Cel Rev Rep. 2021, 1-19. doi:10.1007/s12015-021-10170-6

Camarero-Espinosa, S., Rothen-Rutishauser, B., Weder, C., and Foster, E. J. (2016). Directed Cell Growth in Multi-Zonal Scaffolds for Cartilage Tissue Engineering. Biomaterials 74, 42-52. doi:10.1016/j.biomaterials.2015.09.033

Caron, M. M. J., Emans, P. J., Coolsen, M. M. E., Voss, L., Surtel, D. A. M., Cremers, A., et al. (2012). Redifferentiation of Dedifferentiated Human Articular Chondrocytes: Comparison of 2D and 3D Cultures. Osteoarthritis and Cartilage 20, 1170-1178. doi:10.1016/j.joca.2012.06.016

Castañeda, S., and Vicente, E. F. (2017). Osteoarthritis: More Than Cartilage Degeneration. Clinic Rev. Bone Miner Metab. 15, 69-81. doi:10.1007/s12018017-9228-6

Chen, S., Fu, P., Cong, R., Wu, H., and Pei, M. (2015). Strategies to Minimize Hypertrophy in Cartilage Engineering and Regeneration. Genes Dis. 2, 76-95. doi:10.1016/j.gendis.2014.12.003

Chen, Z., Yan, C., Yan, S., Liu, Q., Hou, M., Xu, Y., et al. (2018). Non-invasive Monitoring of In Vivo Hydrogel Degradation and Cartilage Regeneration by Multiparametric MR Imaging. Theranostics 8, 1146-1158. doi:10.7150/ thno.22514

Chinta, M. L., Velidandi, A., Pabbathi, N. P. P., Dahariya, S., and Parcha, S. R. (2021). Assessment of Properties, Applications and Limitations of Scaffolds Based on Cellulose and its Derivatives for Cartilage Tissue Engineering: A Review. Int J. Biol. Macromolecules 175, 495-515. doi:10.1016/j.ijbiomac.2021.01.196

Cho, H., Kim, D., and Kim, K. (2018). Engineered Co-culture Strategies Using Stem Cells for Facilitated Chondrogenic Differentiation and Cartilage Repair. Biotechnol. Bioproc. E 23, 261-270. doi:10.1007/s12257-018-0149-0

Cielecka, I., Szustak, M., Gendaszewska-Darmach, E., Kalinowska, H., Ryngajłło, M., Maniukiewicz, W., et al. (2018). Novel Bionanocellulose/ к-Carrageenan Composites for Tissue Engineering. Appl. Sci. 8, 1352. doi:10.3390/app8081352

Cochis, A., Grad, S., Stoddart, M. J., Farè, S., Altomare, L., Azzimonti, B., et al. (2017). Bioreactor Mechanically Guided 3D Mesenchymal Stem Cell Chondrogenesis Using a Biocompatible Novel Thermo-Reversible Methylcellulose-Based Hydrogel. Sci. Rep. 7, 45018. doi:10.1038/srep45018

Čolić, M., Tomić, S., and Bekić, M. (2020). Immunological Aspects of Nanocellulose. Immunol. Lett. 222, 80-89. doi:10.1016/J.IMLET.2020.04.004

Csobonyeiova, M., Polak, S., Nicodemou, A., Zamborsky, R., and Danisovic, L. (2021). Ipscs in Modeling and Therapy of Osteoarthritis. Biomedicines 9, 186. doi:10.3390/biomedicines 9020186

Curran, J. M., Chen, R., and Hunt, J. A. (2005). Controlling the Phenotype and Function of Mesenchymal Stem Cells In Vitro by Adhesion to Silane-Modified Clean Glass Surfaces. Biomaterials 26, 7057-7067. doi:10.1016/ j.biomaterials.2005.05.008

Curvello, R., Raghuwanshi, V. S., and Garnier, G. (2019). Engineering Nanocellulose Hydrogels for Biomedical Applications. Adv. Colloid Interf. Sci. 267, 47-61. doi:10.1016/j.cis.2019.03.002

Darling, E. M., Pritchett, P. E., Evans, B. A., Superfine, R., Zauscher, S., and Guilak, F. (2009). Mechanical Properties and Gene Expression of Chondrocytes on Micropatterned Substrates Following Dedifferentiation in Monolayer. Cel. Mol. Bioeng. 2, 395-404. doi:10.1007/s12195-009-0077-3

Davies, R., and Kuiper, N. (2019). Regenerative Medicine: A Review of the Evolution of Autologous Chondrocyte Implantation (ACI) Therapy. Bioengineering 6, 22. doi:10.3390/bioengineering6010022 
Demoor, M., Ollitrault, D., Gomez-Leduc, T., Bouyoucef, M., Hervieu, M., Fabre, H., et al. (2014). Cartilage Tissue Engineering: Molecular Control of Chondrocyte Differentiation for Proper Cartilage Matrix Reconstruction. Biochim. Biophys. Acta (Bba) - Gen. Subjects 1840, 2414-2440. doi:10.1016/ j.bbagen.2014.02.030

Dominici, M., Le Blanc, K., Mueller, I., Slaper-Cortenbach, I., Marini, F. C., Krause, D. S., et al. (2006). Minimal Criteria for Defining Multipotent Mesenchymal Stromal Cells. The International Society for Cellular Therapy Position Statement. Cytotherapy 8, 315-317. doi:10.1080/14653240600855905

Dutta, S. D., Patel, D. K., and Lim, K.-T. (2019). Functional Cellulose-Based Hydrogels as Extracellular Matrices for Tissue Engineering. J. Biol. Eng. 13, 55. doi:10.1186/s13036-019-0177-0

Eschweiler, J., Horn, N., Rath, B., Betsch, M., Baroncini, A., Tingart, M., et al. (2021). The Biomechanics of Cartilage-An Overview. Life 11, 302. doi:10.3390/ life11040302

Eslahi, N., Mahmoodi, A., Mahmoudi, N., Zandi, N., and Simchi, A. (2019). Processing and Properties of Nanofibrous Bacterial Cellulose-Containing Polymer Composites. A Review of Recent Advances for Biomedical Applications. Polym. Rev. 60, 144-170. doi:10.1080/15583724.2019.1663210

Fan, Y., Yue, Z., Lucarelli, E., and Wallace, G. G. (2020). Hybrid Printing Using Cellulose Nanocrystals Reinforced GelMA/HAMA Hydrogels for Improved Structural Integration. Adv. Healthc. Mater. 9, 2001410. doi:10.1002/ adhm.202001410

Favi, P. M., Benson, R. S., Neilsen, N. R., Hammonds, R. L., Bates, C. C., Stephens, C. P., et al. (2013). Cell Proliferation, Viability, and In Vitro Differentiation of Equine Mesenchymal Stem Cells Seeded on Bacterial Cellulose Hydrogel Scaffolds. Mater. Sci. Eng. C 33, 1935-1944. doi:10.1016/j.msec.2012.12.100

Feldmann, E.-M., Sundberg, J., Bobbili, B., Schwarz, S., Gatenholm, P., and Rotter, N. (2013). Description of a Novel Approach to Engineer Cartilage with Porous Bacterial Nanocellulose for Reconstruction of a Human Auricle. J. Biomater. Appl. 28, 626-640. doi:10.1177/0885328212472547

Gatenholm, P., Backdahl, H., Jon Tzavaras, T., Davalos, R. V., and Sano, M. B. (2010). Three-dimensional Bioprinting of Biosynthetic Cellulose (BC) Implants and Scaffolds for Tissue Engineering. U.S. Patent US8691974B2. Available at: https://patents.google.com/patent/US8691974B2/en.

Ge, Z., Li, C., Heng, B. C., Cao, G., and Yang, Z. (2012). Functional Biomaterials for Cartilage Regeneration. J. Biomed. Mater. Res. 100 A, a-n. doi:10.1002/jbm.a.34147

Goldring, M. B. (2012). Chondrogenesis, Chondrocyte Differentiation, and Articular Cartilage Metabolism in Health and Osteoarthritis. Ther. Adv. Musculoskelet. 4, 269-285. doi:10.1177/1759720X12448454

Gonzalez-Fernandez, T., Rathan, S., Hobbs, C., Pitacco, P., Freeman, F. E., Cunniffe, G. M., et al. (2019). Pore-forming Bioinks to Enable SpatioTemporally Defined Gene Delivery in Bioprinted Tissues. J. Controlled Release 301, 13-27. doi:10.1016/j.jconrel.2019.03.006

Gorgieva, S., and Trček, J. (2019). Bacterial Cellulose: Production, Modification and Perspectives in Biomedical Applications. Nanomaterials 9, 1352. doi:10.3390/nano9101352

Grigolo, B., Roseti, L., Fiorini, M., De Franceschi, L., and Facchini, A. (2011). Tissue Engineering Applications: Cartilage Lesions Repair by the Use of Autologous Chondrocytes. Reumatismo 54, 364. doi:10.4081/reumatismo.2002.364

Grigull, N. P., Redeker, J. I., Schmitt, B., Saller, M. M., Schönitzer, V., and MayerWagner, S. (2020). Chondrogenic Potential of Pellet Culture Compared to High-Density Culture on a Bacterial Cellulose Hydrogel. Int. J. Mol. Sci. 21, 2785. doi:10.3390/ijms 21082785

Gu, L., Li, T., Song, X., Yang, X., Li, S., Chen, L., et al. (2020). Preparation and Characterization of Methacrylated Gelatin/bacterial Cellulose Composite Hydrogels for Cartilage Tissue Engineering. Regenerative Biomater. 7, 195-202. doi:10.1093/RB/RBZ050

Halib, N., Perrone, F., Cemazar, M., Dapas, B., Farra, R., Abrami, M., et al. (2017). Potential Applications of Nanocellulose-Containing Materials in the Biomedical Field. Materials 10, 977. doi:10.3390/ma10080977

Hao, T., Wen, N., Cao, J.-K., Wang, H.-B., Lü, S.-H., Liu, T., et al. (2010). The Support of Matrix Accumulation and the Promotion of Sheep Articular Cartilage Defects Repair In Vivo by Chitosan Hydrogels. Osteoarthritis and Cartilage 18, 257-265. doi:10.1016/j.joca.2009.08.007

Helenius, G., Bäckdahl, H., Bodin, A., Nannmark, U., Gatenholm, P., and Risberg, B. (2006). In Vivo biocompatibility of Bacterial Cellulose. J. Biomed. Mater. Res. 76A, 431-438. doi:10.1002/JBM.A.30570
Hodder, E., Duin, S., Kilian, D., Ahlfeld, T., Seidel, J., Nachtigall, C., et al. (2019). Investigating the Effect of Sterilisation Methods on the Physical Properties and Cytocompatibility of Methyl Cellulose Used in Combination with Alginate for 3D-Bioplotting of Chondrocytes. J. Mater. Sci. Mater. Med. 30, 10. doi:10.1007/ s10856-018-6211-9

Hoemann, C. D., Chenite, A., Sun, J., Hurtig, M., Serreqi, A., Lu, Z., et al. (2007). Cytocompatible Gel Formation of Chitosan-Glycerol Phosphate Solutions Supplemented with Hydroxyl Ethyl Cellulose Is Due to the Presence of Glyoxal. J. Biomed. Mater. Res. 83A, 521-529. doi:10.1002/jbm.a.31365

Huang, G. P., Molina, A., Tran, N., Collins, G., and Arinzeh, T. L. (2018). Investigating Cellulose Derived Glycosaminoglycan Mimetic Scaffolds for Cartilage Tissue Engineering Applications. J. Tissue Eng. Regen. Med. 12, e592. doi:10.1002/term.2331

Hunter, D. J., and Bierma-Zeinstra, S. (2019). Osteoarthritis. The Lancet 393, 1745-1759. doi:10.1016/S0140-6736(19)30417-9

Isobe, N., Komamiya, T., Kimura, S., Kim, U.-J., and Wada, M. (2018). Cellulose Hydrogel with Tunable Shape and Mechanical Properties: From Rigid cylinder to Soft Scaffold. Int. J. Biol. Macromolecules 117, 625-631. doi:10.1016/ j.ijbiomac.2018.05.071

Jacek, P., Szustak, M., Kubiak, K., Gendaszewska-Darmach, E., Ludwicka, K., Bielecki, S., et al. (2018). Scaffolds for Chondrogenic Cells Cultivation Prepared from Bacterial Cellulose with Relaxed Fibers Structure Induced Genetically. Nanomaterials 8, 1066. doi:10.3390/nano8121066

James, R., and Laurencin, C. T. (2014). Musculoskeletal Regenerative Engineering: Biomaterials, Structures, and Small Molecules. Adv. Biomater. 2014, 1-12. doi:10.1155/2014/123070

Jarvis, M. C. (2018). Structure of Native Cellulose Microfibrils, the Starting point for Nanocellulose Manufacture. Phil. Trans. R. Soc. A. 376, 20170045. doi:10.1098/rsta.2017.0045

Jessop, Z. M., Al-Sabah, A., Gao, N., Kyle, S., Thomas, B., Badiei, N., et al. (2019). Printability of Pulp Derived crystal, Fibril and Blend Nanocellulose-Alginate Bioinks for Extrusion 3D Bioprinting. Biofabrication 11, 045006. doi:10.1088/ 1758-5090/ab0631

Jing, H., Zhang, X., Gao, M., Luo, K., Fu, W., Yin, M., et al. (2019). Kartogenin Preconditioning Commits Mesenchymal Stem Cells to a Precartilaginous Stage with Enhanced Chondrogenic Potential by Modulating JNK and $\beta$-catenin-related Pathways. FASEB j. 33, 5641-5653. doi:10.1096/ fj.201802137RRR

Jing, W., Chunxi, Y., Yizao, W., Honglin, L., Fang, H., Kerong, D., et al. (2013). Laser Patterning of Bacterial Cellulose Hydrogel and its Modification with Gelatin and Hydroxyapatite for Bone Tissue Engineering. Soft Mater. 11, 173-180. doi:10.1080/1539445X.2011.611204

Jorfi, M., and Foster, E. J. (2015). Recent Advances in Nanocellulose for Biomedical Applications. J. Appl. Polym. Sci. 132, a-n. doi:10.1002/APP.41719

Khan, S., Siddique, R., Huanfei, D., Shereen, M. A., Nabi, G., Bai, Q., et al. (2021). Perspective Applications and Associated Challenges of Using Nanocellulose in Treating Bone-Related Diseases. Front. Bioeng. Biotechnol. 9, 616555. doi:10.3389/FBIOE.2021.616555

Kilian, D., Ahlfeld, T., Akkineni, A. R., Bernhardt, A., Gelinsky, M., and Lode, A. (2020). 3D Bioprinting of Osteochondral Tissue Substitutes - In Vitrochondrogenesis in Multi-Layered Mineralized Constructs. Sci. Rep. 10, 8277. doi:10.1038/s41598-020-65050-9

Klemm, D., Kramer, F., Moritz, S., Lindström, T., Ankerfors, M., Gray, D., et al. (2011). Nanocelluloses: A New Family of Nature-Based Materials. Angew. Chem. Int. Ed. 50, 5438-5466. doi:10.1002/anie.201001273

Kuhnt, T., and Camarero-Espinosa, S. (2021). Additive Manufacturing of Nanocellulose Based Scaffolds for Tissue Engineering: Beyond a Reinforcement Filler. Carbohydr. Polym. 252, 117159. doi:10.1016/ j.carbpol.2020.117159

Kumbhar, J., Jadhav, S., Bodas, D., Barhanpurkar-Naik, A., Wani, M., Paknikar, K., et al. (2017). In Vitro and In Vivo Studies of a Novel Bacterial Cellulose-Based Acellular Bilayer Nanocomposite Scaffold for the Repair of Osteochondral Defects. Int. J. Nanomedicine 12, 6437-6459. doi:10.2147/IJN.S137361

Kurian, A. G., Singh, R. K., Patel, K. D., Lee, J.-H., and Kim, H.-W. (2021). Multifunctional GelMA Platforms with Nanomaterials for Advanced Tissue Therapeutics. Bioactive Mater. doi:10.1016/J.BIOACTMAT.2021.06.027

Langer, R., and Vacanti, J. (1993). Tissue Engineering. Science 260, 920-926. doi:10.1126/science.8493529 
Lee, K.-Y., Buldum, G., Mantalaris, A., and Bismarck, A. (2014). More Than Meets the Eye in Bacterial Cellulose: Biosynthesis, Bioprocessing, and Applications in Advanced Fiber Composites. Macromol. Biosci. 14, 10-32. doi:10.1002/ mabi.201300298

Leone, G., Fini, M., Torricelli, P., Giardino, R., and Barbucci, R. (2008). An Amidated Carboxymethylcellulose Hydrogel for Cartilage Regeneration. J. Mater. Sci. Mater. Med. 19, 2873-2880. doi:10.1007/s10856-008-3412-7

Li, X. G., Park, I.-S., Choi, B. H., Kim, U.-J., and Min, B.-H. (2020). In Vivo Bioreactor Using Cellulose Membrane Benefit Engineering Cartilage by Improving the Chondrogenesis and Modulating the Immune Response. Tissue Eng. Regen. Med. 17, 165-181. doi:10.1007/s13770-019-00236-5

Lien, S.-M., Ko, L.-Y., and Huang, T.-J. (2009). Effect of Pore Size on ECM Secretion and Cell Growth in Gelatin Scaffold for Articular Cartilage Tissue Engineering. Acta Biomater. 5, 670-679. doi:10.1016/j.actbio.2008.09.020

Lin, S., Sangaj, N., Razafiarison, T., Zhang, C., and Varghese, S. (2011). Influence of Physical Properties of Biomaterials on Cellular Behavior. Pharm Res. 28 (6), 1422-1430. doi:10.1007/s11095-011-0378-9

Liu, Y., Zhou, G., and Cao, Y. (2017). Recent Progress in Cartilage Tissue Engineering-Our Experience and Future Directions. Engineering 3, 28-35. doi:10.1016/J.ENG.2017.01.010

Loeser, R. F., Collins, J. A., and Diekman, B. O. (2016). Ageing and the Pathogenesis of Osteoarthritis. Nat. Rev. Rheumatol. 12, 412-420. doi:10.1038/nrrheum.2016.65

Ludwicka, K., Kolodziejczyk, M., Gendaszewska-Darmach, E., Chrzanowski, M., Jedrzejczak-Krzepkowska, M., Rytczak, P., et al. (2019). Stable Composite of Bacterial Nanocellulose and Perforated Polypropylene Mesh for Biomedical Applications. J. Biomed. Mater. Res. 107, 978-987. doi:10.1002/jbm.b.34191

Mahendiran, B., Muthusamy, S., Sampath, S., Jaisankar, S. N., Popat, K. C., Selvakumar, R., et al. (2021). Recent Trends in Natural Polysaccharide Based Bioinks for Multiscale 3D Printing in Tissue Regeneration: A Review. Int. J. Biol. Macromolecules 183, 564-588. doi:10.1016/j.ijbiomac.2021.04.179

Makris, E. A., Gomoll, A. H., Malizos, K. N., Hu, J. C., and Athanasiou, K. A. (2015). Repair and Tissue Engineering Techniques for Articular Cartilage. Nat. Rev. Rheumatol. 11, 21-34. doi:10.1038/nrrheum.2014.157

Mao, Y., Hoffman, T., Wu, A., and Kohn, J. (2018). An Innovative Laboratory Procedure to Expand Chondrocytes with Reduced Dedifferentiation. Cartilage 9, 202-211. doi:10.1177/1947603517746724

Markstedt, K., Mantas, A., Tournier, I., Martínez Ávila, H., Hägg, D., and Gatenholm, P. (2015). 3D Bioprinting Human Chondrocytes with Nanocellulose-Alginate Bioink for Cartilage Tissue Engineering Applications. Biomacromolecules 16, 1489-1496. doi:10.1021/acs.biomac.5b00188

Martínez Ávila, H., Feldmann, E.-M., Pleumeekers, M. M., Nimeskern, L., Kuo, W., de Jong, W. C., et al. (2015). Novel Bilayer Bacterial Nanocellulose Scaffold Supports Neocartilage Formation In Vitro and In Vivo. Biomaterials 44, 122-133. doi:10.1016/j.biomaterials.2014.12.025

Martínez Ávila, H., Schwarz, S., Feldmann, E.-M., Mantas, A., von Bomhard, A., Gatenholm, P., et al. (2014). Biocompatibility Evaluation of Densified Bacterial Nanocellulose Hydrogel as an Implant Material for Auricular Cartilage Regeneration. Appl. Microbiol. Biotechnol. 98, 7423-7435. doi:10.1007/ s00253-014-5819-z

Martínez Ávila, H., Schwarz, S., Rotter, N., and Gatenholm, P. (2016). 3D Bioprinting of Human Chondrocyte-Laden Nanocellulose Hydrogels for Patient-specific Auricular Cartilage Regeneration. Bioprinting 1-2, 22-35. doi:10.1016/j.bprint.2016.08.003

Maumus, M., Manferdini, C., Toupet, K., Peyrafitte, J.-A., Ferreira, R., Facchini, A., et al. (2013). Adipose Mesenchymal Stem Cells Protect Chondrocytes from Degeneration Associated with Osteoarthritis. Stem Cel Res. 11, 834-844. doi:10.1016/j.scr.2013.05.008

Mayer-Wagner, S., Schiergens, T. S., Sievers, B., Redeker, J. I., Schmitt, B., Buettner, A., et al. (2011). Scaffold-free 3D Cellulose Acetate Membrane-Based Cultures Form Large Cartilaginous Constructs. J. Tissue Eng. Regen. Med. 5, 151-155. doi:10.1002/term.300

Mebarki, M., Abadie, C., Larghero, J., and Cras, A. (2021). Human Umbilical CordDerived Mesenchymal Stem/stromal Cells: a Promising Candidate for the Development of Advanced Therapy Medicinal Products. Stem Cel Res Ther 12, 1-10. doi:10.1186/s13287-021-02222-y

Medronho, B., Romano, A., Miguel, M. G., Stigsson, L., and Lindman, B. (2012). Rationalizing Cellulose (In)solubility: Reviewing Basic Physicochemical
Aspects and Role of Hydrophobic Interactions. Cellulose 19, 581-587. doi:10.1007/S10570-011-9644-6

Menezes, R., and Arinzeh, T. L. (2020). Comparative Study of Electrospun Scaffolds Containing Native GAGs and a GAG Mimetic for Human Mesenchymal Stem Cell Chondrogenesis. Ann. Biomed. Eng. 48, 2040-2052. doi:10.1007/s10439-020-02499-9

Merceron, C., Portron, S., Masson, M., Fellah, B. H., Gauthier, O., Lesoeur, J., et al. (2010). Cartilage Tissue Engineering: From Hydrogel to Mesenchymal Stem Cells. Biomed. Mater. Eng., 20, 159-166. doi:10.3233/ BME-2010-0627

Merceron, C., Portron, S., Masson, M., Lesoeur, J., Fellah, B. H., Gauthier, O., et al. (2011). The Effect of Two- and Three-Dimensional Cell Culture on the Chondrogenic Potential of Human Adipose-Derived Mesenchymal Stem Cells after Subcutaneous Transplantation with an Injectable Hydrogel. Cel Transpl. 20, 1575-1588. doi:10.3727/096368910X557191

Miśkiewicz, S., Grobelski, B., Pasieka, Z., and Miśkiewicz, M. (2019). The Testing of an Artificial Modified Bacterial Cellulose Auricle Skeleton in an Animal Model. Pol. Przegl Chir 91, 7-11. doi:10.5604/01.3001.0012.8551

Möller, T., Amoroso, M., Hägg, D., Brantsing, C., Rotter, N., Apelgren, P., et al. (2017). In Vivo Chondrogenesis in 3D Bioprinted Human Cell-Laden Hydrogel Constructs. Plast. Reconstr. Surg. Glob. Open 5, e1227. doi:10.1097/ GOX.0000000000001227

Müller, F. A., Müller, L., Hofmann, I., Greil, P., Wenzel, M. M., and Staudenmaier, R. (2006). Cellulose-based Scaffold Materials for Cartilage Tissue Engineering. Biomaterials 27, 3955-3963. doi:10.1016/j.biomaterials.2006.02.031

Müller, M., Öztürk, E., Arlov, Ø., Gatenholm, P., and Zenobi-Wong, M. (2017). Alginate Sulfate-Nanocellulose Bioinks for Cartilage Bioprinting Applications. Ann. Biomed. Eng. 45, 210-223. doi:10.1007/s10439-016-1704-5

Naderi-Meshkin, H., Andreas, K., Matin, M. M., Sittinger, M., Bidkhori, H. R., Ahmadiankia, N., et al. (2014). Chitosan-based Injectable Hydrogel as a Promising In Situ Forming Scaffold for Cartilage Tissue Engineering. Cell Biol Int 38, 72-84. doi:10.1002/cbin.10181

Namkaew, J., Laowpanitchakorn, P., Sawaddee, N., Jirajessada, S., Honsawek, S., and Yodmuang, S. (2021). Carboxymethyl Cellulose Entrapped in a Poly(vinyl) Alcohol Network: Plant-Based Scaffolds for Cartilage Tissue Engineering. Molecules 26, 578. doi:10.3390/molecules 26030578

Nasri-Nasrabadi, B., Mehrasa, M., Rafienia, M., Bonakdar, S., Behzad, T., and Gavanji, S. (2014). Porous Starch/cellulose Nanofibers Composite Prepared by Salt Leaching Technique for Tissue Engineering. Carbohydr. Polym. 108, 232-238. doi:10.1016/j.carbpol.2014.02.075

Ngadimin, K. D., Stokes, A., Gentile, P., and Ferreira, A. M. (2021). Biomimetic Hydrogels Designed for Cartilage Tissue Engineering. Biomater. Sci. 9, 4246-4259. doi:10.1039/d0bm01852j

Nguyen, D., Hägg, D. A., Forsman, A., Ekholm, J., Nimkingratana, P., Brantsing, C., et al. (2017). Cartilage Tissue Engineering by the 3D Bioprinting of iPS Cells in a Nanocellulose/Alginate Bioink. Sci. Rep. 7, 658. doi:10.1038/s41598-01700690-y

Ni, T., Liu, M., Zhang, Y., Cao, Y., and Pei, R. (2020). 3D Bioprinting of Bone Marrow Mesenchymal Stem Cell-Laden Silk Fibroin Double Network Scaffolds for Cartilage Tissue Repair. Bioconjug. Chem. 31, 1938-1947. doi:10.1021/ acs.bioconjchem.0c00298

Ogura, T., Mosier, B. A., Bryant, T., and Minas, T. (2017). A 20-Year Follow-Up after First-Generation Autologous Chondrocyte Implantation. Am. J. Sports Med. 45, 2751-2761. doi:10.1177/0363546517716631

Oprea, M., and Voicu, S. I. (2020). Cellulose Composites with Graphene for Tissue Engineering Applications. Materials 13, 5347. doi:10.3390/ ma13235347

Osorio, M., Cañas, A., Puerta, J., Díaz, L., Naranjo, T., Ortiz, I., et al. (2019). Ex Vivo and In Vivo Biocompatibility Assessment (Blood and Tissue) of Three-Dimensional Bacterial Nanocellulose Biomaterials for Soft Tissue Implants. Sci. Rep. 9, 10553. doi:10.1038/s41598-019-46918-x

Peng, Z., Sun, H., Bunpetch, V., Koh, Y., Wen, Y., Wu, D., et al. (2021). The Regulation of Cartilage Extracellular Matrix Homeostasis in Joint Cartilage Degeneration and Regeneration. Biomaterials 268, 120555. doi:10.1016/ j.biomaterials.2020.120555

Peterson, L., Vasiliadis, H. S., Brittberg, M., and Lindahl, A. (2010). Autologous Chondrocyte Implantation. Am. J. Sports Med. 38, 1117-1124. doi:10.1177/ 0363546509357915 
Piras, C. C., Fernández-Prieto, S., and De Borggraeve, W. M. (2017). Nanocellulosic Materials as Bioinks for 3D Bioprinting. Biomater. Sci. 5, 1988-1992. doi:10.1039/c7bm00510e

Portocarrero Huang, G., Menezes, R., Vincent, R., Hammond, W., Rizio, L., Collins, G., et al. (2017). Gelatin Scaffolds Containing Partially Sulfated Cellulose Promote Mesenchymal Stem Cell Chondrogenesis. Tissue Eng. A 23, 1011-1021. doi:10.1089/ten.TEA.2016.0461

Pourbashir, S., Shahrousvand, M., and Ghaffari, M. (2020). Preparation and Characterization of Semi-IPNs of Polycaprolactone/poly (Acrylic Acid)/ cellulosic Nanowhisker as Artificial Articular Cartilage. Int. J. Biol. Macromolecules 142, 298-310. doi:10.1016/j.ijbiomac.2019.09.101

Pretzel, D., Linss, S., Ahrem, H., Endres, M., Kaps, C., Klemm, D., et al. (2013). A Novel In Vitro Bovine Cartilage Punch Model for Assessing the Regeneration of Focal Cartilage Defects with Biocompatible Bacterial Nanocellulose. Arthritis Res. Ther. 15, R59. doi:10.1186/ar4231

Rederstorff, E., Rethore, G., Weiss, P., Sourice, S., Beck-Cormier, S., Mathieu, E., et al. (2017). Enriching a Cellulose Hydrogel with a Biologically Active marine Exopolysaccharide for Cell-Based Cartilage Engineering. J. Tissue Eng. Regen. Med. 11, 1152-1164. doi:10.1002/term.2018

Roushangar Zineh, B., Shabgard, M. R., and Roshangar, L. (2018). Mechanical and Biological Performance of Printed Alginate/methylcellulose/halloysite Nanotube/polyvinylidene Fluoride Bio-Scaffolds. Mater. Sci. Eng. C 92, 779-789. doi:10.1016/j.msec.2018.07.035

Ryngajłło, M., Jędrzejczak-Krzepkowska, M., Kubiak, K., Ludwicka, K., and Bielecki, S. (2020). Towards Control of Cellulose Biosynthesis by Komagataeibacter Using Systems-Level and Strain Engineering Strategies: Current Progress and Perspectives. Appl. Microbiol. Biotechnol. 104, 6565-6585. doi:10.1007/s00253-020-10671-3

Sá-Lima, H., Tuzlakoglu, K., Mano, J. F., and Reis, R. L. (2011). Thermoresponsive poly(N-Isopropylacrylamide)-G-Methylcellulose Hydrogel as a ThreeDimensional Extracellular Matrix for Cartilage-Engineered Applications. J. Biomed. Mater. Res. 98A, 596-603. doi:10.1002/jbm.a.33140

Schütz, K., Placht, A.-M., Paul, B., Brüggemeier, S., Gelinsky, M., and Lode, A. (2017). Three-dimensional Plotting of a Cell-Laden Alginate/methylcellulose Blend: towards Biofabrication of Tissue Engineering Constructs with Clinically Relevant Dimensions. J. Tissue Eng. Regen. Med. 11, 1574-1587. doi:10.1002/ term. 2058

Seddiqi, H., Oliaei, E., Honarkar, H., Jin, J., Geonzon, L. C., Bacabac, R. G., et al. (2021). Cellulose and its Derivatives: towards Biomedical Applications. Cellulose 28, 1893-1931. doi:10.1007/s10570-020-03674-w

Shrestha, R., Palat, A., Punnoose, A. M., Joshi, S., Ponraju, D., and Paul, S. F. D. (2016). Electrospun Cellulose Acetate Phthalate Nanofibrous Scaffolds Fabricated Using Novel Solvent Combinations Biocompatible for Primary Chondrocytes and Neurons. Tissue and Cell 48, 634-643. doi:10.1016/ j.tice.2016.07.007

Silva, M. d. A., Leite, Y. K. d. C., Carvalho, C. E. S. d., Feitosa, M. L. T., Alves, M. M. d. M., Carvalho, F. A. d. A., et al. (2018). Behavior and Biocompatibility of Rabbit Bone Marrow Mesenchymal Stem Cells with Bacterial Cellulose Membrane. PeerJ 6, e4656. doi:10.7717/peerj.4656

Singh, N., Rahatekar, S. S., Koziol, K. K. K., Ng, T. S., Patil, A. J., Mann, S., et al. (2013). Directing Chondrogenesis of Stem Cells with Specific Blends of Cellulose and Silk. Biomacromolecules 14, 1287-1298. doi:10.1021/bm301762p

Sophia Fox, A. J., Bedi, A., and Rodeo, S. A. (2009). The Basic Science of Articular Cartilage: Structure, Composition, and Function. Sports Health 1, 461-468. doi:10.1177/1941738109350438

Stampoultzis, T., Karami, P., and Pioletti, D. P. (2021). Thoughts on Cartilage Tissue Engineering: A 21st century Perspective. Curr. Res. Translational Med. 69, 103299. doi:10.1016/j.retram.2021.103299

Stefaniak, A. B., Seehra, M. S., Fix, N. R., and Leonard, S. S. (2014). Lung Biodurability and Free Radical Production of Cellulose Nanomaterials. Inhalation Toxicol. 26, 733-749. doi:10.3109/08958378.2014.948650

Svensson, A., Nicklasson, E., Harrah, T., Panilaitis, B., Kaplan, D. L., Brittberg, M., et al. (2005). Bacterial Cellulose as a Potential Scaffold for Tissue Engineering of Cartilage. Biomaterials 26, 419-431. doi:10.1016/ j.biomaterials.2004.02.049

Talaat, W., Aryal Ac, S., Al Kawas, S., Samsudin, A. R., Kandile, N. G., Harding, D. R., et al. (2020). Nanoscale Thermosensitive Hydrogel Scaffolds Promote the Chondrogenic Differentiation of Dental Pulp Stem and Progenitor Cells: A
Minimally Invasive Approach for Cartilage Regeneration. Int. J. Nanomedicine 15, 7775-7789. doi:10.2147/IJN.S274418

Tang, A., Ji, J., Li, J., Liu, W., Wang, J., Sun, Q., et al. (2021). Nanocellulose/PEGDA Aerogels with Tunable Poisson's Ratio Fabricated by Stereolithography for Mouse Bone Marrow Mesenchymal Stem Cell Culture. Nanomaterials 11, 603-618. doi:10.3390/nano11030603

Tanpichai, S., Quero, F., Nogi, M., Yano, H., Young, R. J., Lindström, T., et al. (2012). Effective Young's Modulus of Bacterial and Microfibrillated Cellulose Fibrils in Fibrous Networks. Biomacromolecules 13, 1340-1349. doi:10.1021/ bm300042t

Taokaew, S., Phisalaphong, M., and Zhang Newby, B.-m. (2014). In Vitro behaviors of Rat Mesenchymal Stem Cells on Bacterial Celluloses with Different Moduli. Mater. Sci. Eng. C 38, 263-271. doi:10.1016/ j.msec.2014.02.005

Toit, L., Kumar, P., Choonara, Y., and Pillay, V. (2020). Advanced 3D-Printed Systems and Nanosystems for Drug Delivery and Tissue Engineering. 1st Edition. First. Woodhead Publishing Available at: https://www.elsevier.com/books/ advanced-3d-printed-systems-and-nanosystems-for-drug-delivery-and-tissueengineering/toit/978-0-12-818471-4 (Accessed June 14, 2021).

Tortorella, S., Vetri Buratti, V., Maturi, M., Sambri, L., Comes Franchini, M., and Locatelli, E. (2020). Surface-Modified Nanocellulose for Application in Biomedical Engineering and Nanomedicine: A Review. Int. J. Nanomedicine 15, 9909-9937. doi:10.2147/IJN.S266103

Vega, S., Kwon, M. Y., Kwon, M., and Burdick, J. (2017). Recent Advances in Hydrogels for Cartilage Tissue Engineering. eCM 33, 59-75. doi:10.22203/ eCM.v033a05

Vinatier, C., Gauthier, O., Fatimi, A., Merceron, C., Masson, M., Moreau, A., et al. (2009). An Injectable Cellulose-Based Hydrogel for the Transfer of Autologous Nasal Chondrocytes in Articular Cartilage Defects. Biotechnol. Bioeng. 102, 1259-1267. doi:10.1002/bit.22137

Vinatier, C., Magne, D., Moreau, A., Gauthier, O., Malard, O., Vignes-Colombeix, C., et al. (2007). Engineering Cartilage with Human Nasal Chondrocytes and a Silanized Hydroxypropyl Methylcellulose Hydrogel. J. Biomed. Mater. Res. 80A, 66-74. doi:10.1002/jbm.a.30867

Vinatier, C., Magne, D., Weiss, P., Trojani, C., Rochet, N., Carle, G. F., et al. (2005). A Silanized Hydroxypropyl Methylcellulose Hydrogel for the ThreeDimensional Culture of Chondrocytes. Biomaterials 26, 6643-6651. doi:10.1016/j.biomaterials.2005.04.057

Walter, S. G., Ossendorff, R., and Schildberg, F. A. (2019). Articular Cartilage Regeneration and Tissue Engineering Models: a Systematic Review. Arch. Orthop. Trauma Surg. 139, 305-316. doi:10.1007/s00402-018-3057-z

Wang, Y., Yuan, X., Yu, K., Meng, H., Zheng, Y., Peng, J., et al. (2018). Fabrication of Nanofibrous Microcarriers Mimicking Extracellular Matrix for Functional Microtissue Formation and Cartilage Regeneration. Biomaterials 171, 118-132. doi:10.1016/j.biomaterials.2018.04.033

Wuputra, K., Ku, C.-C., Wu, D.-C., Lin, Y.-C., Saito, S., and Yokoyama, K. K. (2020). Prevention of Tumor Risk Associated with the Reprogramming of Human Pluripotent Stem Cells. J. Exp. Clin. Cancer Res. 39, 1-24. doi:10.1186/ s13046-020-01584-0

Xu, W., Wang, X., Sandler, N., Willför, S., and Xu, C. (2018). Three-Dimensional Printing of Wood-Derived Biopolymers: A Review Focused on Biomedical Applications. ACS Sustain. Chem. Eng. 6, 5663-5680. doi:10.1021/ acssuschemeng.7b03924

Yadav, V., Paniliatis, B. J., Shi, H., Lee, K., Cebe, P., and Kaplan, D. L. (2010). Novel In Vivo -Degradable Cellulose-Chitin Copolymer from Metabolically Engineered Gluconacetobacter Xylinus. Appl. Environ. Microbiol. 76, 6257-6265. doi:10.1128/AEM.00698-10

Yadav, V., Sun, L., Panilaitis, B., and Kaplan, D. L. (2015). In Vitrochondrogenesis with Lysozyme Susceptible Bacterial Cellulose as a Scaffold. J. Tissue Eng. Regen. Med. 9, E276-E288. doi:10.1002/term.1644

Yanamala, N., Farcas, M. T., Hatfield, M. K., Kisin, E. R., Kagan, V. E., Geraci, C. L., et al. (2014). In Vivo Evaluation of the Pulmonary Toxicity of Cellulose Nanocrystals: A Renewable and Sustainable Nanomaterial of the Future. ACS Sustain. Chem. Eng. 2, 1691-1698. doi:10.1021/SC500153K

Yang, W., Zheng, Y., Chen, J., Zhu, Q., Feng, L., Lan, Y., et al. (2019a). Preparation and Characterization of the Collagen/cellulose Nanocrystals/USPIO Scaffolds Loaded Kartogenin for Cartilage Regeneration. Mater. Sci. Eng. C 99, 1362-1373. doi:10.1016/j.msec.2019.02.071 
Yang, W., Zhu, P., Huang, H., Zheng, Y., Liu, J., Feng, L., et al. (2019b). Functionalization of Novel Theranostic Hydrogels with Kartogenin-Grafted USPIO Nanoparticles to Enhance Cartilage Regeneration. ACS Appl. Mater. Inter. 11, 34744-34754. doi:10.1021/acsami.9b12288

Yin, N., Stilwell, M. D., Santos, T. M. A., Wang, H., and Weibel, D. B. (2015). Agarose Particle-Templated Porous Bacterial Cellulose and its Application in Cartilage Growth In Vitro. Acta Biomater. 12, 129-138. doi:10.1016/j.actbio.2014.10.019

Zha, K., Li, X., Yang, Z., Tian, G., Sun, Z., Sui, X., et al. (2021). Heterogeneity of Mesenchymal Stem Cells in Cartilage Regeneration: from Characterization to Application. Npj Regen. Med. 6, 1-15. doi:10.1038/s41536-021-00122-6

Zhang, Q., Lu, H., Kawazoe, N., and Chen, G. (2014). Pore Size Effect of Collagen Scaffolds on Cartilage Regeneration. Acta Biomater. 10, 2005-2013. doi:10.1016/j.actbio.2013.12.042

Zhang, S., Huang, D., Lin, H., Xiao, Y., and Zhang, X. (2020). Cellulose Nanocrystal Reinforced Collagen-Based Nanocomposite Hydrogel with Self-Healing and Stress-Relaxation Properties for Cell Delivery. Biomacromolecules 21, 2400-2408. doi:10.1021/acs.biomac.0c00345

Zhao, X., Hu, D. A., Wu, D., He, F., Wang, H., Huang, L., et al. (2021). Applications of Biocompatible Scaffold Materials in Stem Cell-Based Cartilage Tissue Engineering. Front. Bioeng. Biotechnol. 9, 603444. doi:10.3389/fbioe.2021.603444

Zhu, X., Chen, T., Feng, B., Weng, J., Duan, K., Wang, J., et al. (2018). Biomimetic Bacterial Cellulose-Enhanced Double-Network Hydrogel with Excellent Mechanical Properties Applied for the Osteochondral
Defect Repair. ACS Biomater. Sci. Eng. 4, 3534-3544. doi:10.1021/ acsbiomaterials. 8 b00682

Zylińska, B., Silmanowicz, P., Sobczyńska-Rak, A., Jarosz, Ł., and Szponder, T. (2018). Treatment of Articular Cartilage Defects: Focus on Tissue Engineering. Vivo 32, 1289-1300. doi:10.21873/invivo.11379

Conflict of Interest: The authors declare that the research was conducted in the absence of any commercial or financial relationships that could be construed as a potential conflict of interest.

Publisher's Note: All claims expressed in this article are solely those of the authors and do not necessarily represent those of their affiliated organizations, or those of the publisher, the editors and the reviewers. Any product that may be evaluated in this article, or claim that may be made by its manufacturer, is not guaranteed or endorsed by the publisher.

Copyright (c) 2021 Szustak and Gendaszewska-Darmach. This is an open-access article distributed under the terms of the Creative Commons Attribution License (CC $B Y$ ). The use, distribution or reproduction in other forums is permitted, provided the original author(s) and the copyright owner(s) are credited and that the original publication in this journal is cited, in accordance with accepted academic practice. No use, distribution or reproduction is permitted which does not comply with these terms. 


\section{GLOSSARY}

ACAN aggrecan coding gene

a-CNCs aldehyde-functionalized cellulose nanocrystals

ALP alkaline phosphatase

ACI autologous chondrocyte implantation

ACs articular chondrocytes

ATSCs stem cells from adipose tissue

BM-MSCs bone marrow mesenchymal stem cells

BMP bone morphogenetic protein

BNC bacterial cellulose

CA cellulose acetate

CaP carbonated apatite

CBFB transcription factor core binding factor beta subunit

CMC carboxymethylcellulose

CMCA amidic derivative of CMC

CNC cellulose nanocrystals

COL1A1 collagen type I al chain coding gene

COL2A1 collagen type II al chain coding gene

COL10A1 X collagen type $X$ al chain coding gene

COMP cartilage oligomeric matrix protein

CPC calcium phosphate cement

CS chitosan

2D two-dimensional

3D three-dimensional

Dex dextran

ECM extracellular matrix

ESCs embryonic stem cells

FGF fibroblast growth factor

FN fibronectin

GAG glycosaminoglycan

GelMA gelatin methacrylate

GP $\beta$-glycerophosphate

HA hyaluronic acid

HAMA hyaluronic acid methacrylate

hBM-MSCs human bone marrow mesenchymal stem cells hDPSCs human dental pulp stem and progenitor cells

$\mathbf{H} \& \mathbf{E}$ hematoxylin and eosin
HEC hydroxyethylcellulose

hNCs human nasoseptal chondrocytes

HPC hydroxypropyl cellulose

HPMC hydroxypropylmethylcellulose

IFP-MSCs infrapatellar fat pad derived mesenchymal stem cells

iPSCs induced pluripotent stem cells

KNG kartogenin

LiBr lithium bromide

MACI matrix-induced autologous chondrocyte implantation

MC methylcellulose

MMP matrix metalloproteinase

MRI magnetic resonance imaging

MSCs mesenchymal stem cells

$\mathrm{NaCS}$ completely sulfated version of sodium cellulose

NC nanocellulose osteoarthritis

NFC nanofibrillated cellulose, OA

PAA poly(acrylic acid)

PCL polycaprolactone

PEGDA polyethylene glycol diacrylate

PLA poly(d,l-lactide)

P-CNC phosphated cellulose nanocrystals

pSC partially sulfated cellulose

PU polyurethane

RUNX Runt-related transcription factor semi-IPNs semi-interpenetrating polymer networks

sCMC sulfated carboxymethylcellulose

S-CNC sulfated cellulose nanocrystals

sGAG sulfonated glycosaminoglycan

SF silk fibroin

Si-HPMC silanized-hydroxypropyl methylcellulose

SOX9 SRY-Box Transcription Factor 9

UC-MSCs umbilical cord mesenchymal stem cells

TE tissue engineering

TGF- $\beta$ transforming growth factor $\beta$

USPIO ultrasmall superparamagnetic iron oxide

VEGF vascular endothelial growth factor 